Article

\title{
Effects of Dissipative Systems on the Seismic Behavior of Irregular Buildings-Two Case Studies
}

\author{
Marco Miani *, Caterina Di Marco, Giada Frappa and Margherita Pauletta \\ Polytechnic Department of Engineering and Architecture, University of Udine, Via delle Scienze, \\ 206-33100 Udine, Italy; dimarco.caterina@spes.uniud.it (C.D.M.); giada.frappa@uniud.it (G.F.); \\ margherita.pauletta@uniud.it (M.P.) \\ * Correspondence: miani.marco.2@spes.uniud.it; Tel.: +39-0432-558065
}

Received: 1 October 2020; Accepted: 5 November 2020; Published: 7 November 2020

\begin{abstract}
Conservation of heritage buildings has become a very important issue in many countries, as it is in Italy, where a great number of existing buildings of historical-artistic importance are seismically vulnerable. To improve existing building behavior, researchers focus on the design of retrofit interventions. This paper presents the application of energy dissipation devices in the retrofit of two existing Reinforced Concrete (RC) buildings, both irregular in plan and along their heights, designed for gravitational loads only. These buildings are representative of Italian public housing built in the 1960s and early 1970s. Technical information and mechanical properties of materials are presented, and non-linear analyses are carried out to evaluate the buildings' behavior under earthquake loads. Many of their structural members do not satisfy the verifications required by the Italian Building Code. Retrofit interventions with buckling-restrained axial dampers in one building and viscous fluid dampers in the other are proposed. The verifications of the retrofitted buildings and the amount of the energy absorbed by the devices with respect to that absorbed by the unretrofitted buildings show the effectiveness of the proposed interventions. Moreover, it is demonstrated that adequate dispositions of the dissipative devices in plan and along the height increase the torsional stiffness of the buildings, improving their structural response under seismic action.
\end{abstract}

Keywords: existing buildings; irregular structure; case studies; seismic retrofit; energy dissipation device

\section{Introduction}

In Italy, over the last twenty years, the occurrence of severe earthquakes has highlighted the extreme seismic risk of heritage buildings and, as consequence, the importance of realizing seismic protection interventions. In fact, although Italy is characterized by high seismic hazard, existing buildings on its territory are very old, and most of them, including many Reinforced Concrete (RC) structures, do not satisfy the basic performance requirements set by the latest building code for seismic resistance. For this reason, seismic protection of Italian heritage buildings has become a very sensitive topic among designers and public administrations.

As shown in data compiled by the Italian National Institute of Statistics (ISTAT) in 2011, there are $14,515,795$ buildings in Italy, of which $84 \%$ are residential buildings. Within this $84 \%, 57 \%$ are identified as buildings characterized by masonry bearing walls, $30 \%$ are buildings that have a RC bearing structure, and $13 \%$ are constructions in which the bearing structure is made with other materials. Furthermore, $57 \%$ of residential buildings were built before the 1970 s, 36\% were built between 1971 and 2000, and 7\% were built after 2000. Since the first seismic code was introduced in Italy in 1974, on the basis of these data it is possible to conclude that more than $60 \%$ of Italian existing buildings are exposed to seismic risk, being designed without a seismic code. In general, older buildings are more 
vulnerable to seismic events. Many of them are also part of the Italian historical monumental heritage. For this reason, seismic protection actions should be focused not only on the design of new buildings able to resist to seismic excitation, but also on the design of solutions that decrease the seismic risk of the existing built heritage.

Comprehension of the buildings' weaknesses is the first step in defining a strategy of intervention to improve their seismic behavior and hence reduce the seismic risk. To this end, it is important to perform an adequate analysis of the building, taking account of the historical analysis, the construction stages, the actual state, in terms of damage and/or cracks, and the characteristics of the materials [1].

Before the introduction of the first seismic code in 1974, in Italy structures were generally designed only for gravity load, not considering seismic action. Only about fifteen years ago did modern codes improve building design procedures by introducing capacity design. Considering the prescriptions of these codes, it results that a huge number of existing buildings have not adequate capacity to avoid failure. The weaknesses of these buildings are often connected to one or more of the following issues: inadequate lateral stiffness and resistance, non-negligible stiffness variation between two successive floors, low torsional stiffness, presence of smooth reinforcing bars, and/or inadequate details for ductile behavior, such as too large spacing of transverse shear reinforcement. Based on observation of the effects of past earthquakes in the country, most RC building collapses or damage in Italy can be attributed to column shear failure, soft story mechanism, diagonal cracking of the beam-column joint, total or partial ejecting of masonry infills, and/or loss of cover concrete [2-6].

There are many strategies that can be followed to improve the behavior of existing buildings. Among the more modern strategies, passive energy dissipation systems, which improve the dissipative capacity of the structure, are taken into consideration in this paper. These systems have been used in different types of buildings, primarily with RC structures, such as residential, school and industrial buildings [7-13]. They exhibit good performance and require only a short interruption in the use of the buildings for their installation.

This research work aims to prove that dissipative systems are effective, not only for the energy dissipation capacity, but also in improving the seismic response of irregular buildings.

Two case studies represented by RC residential buildings, both irregular in plan and along their heights, are analyzed. The buildings are both located in Udine, Italy, and are designed for gravity loads only. They are representative of many structures that were built during the Italian national program of construction for worker housing, which was launched in 1963 and managed by Management of Workers' Houses (GESCAL). Interventions by means of Buckling-Restrained Axial Dampers (BRADs) for one building and viscoelastic fluid dampers for the other are presented. To evaluate the seismic response of the as-built structures and retrofitted ones, Finite Element Models (FEMs) are implemented through the software SAP2000 (Computers and Structures, Inc., Walnut Creek, CA, USA), and nonlinear dynamic analyses are performed.

The improvement of structural members' verifications due to the introduction of the dissipative systems is demonstrated, by considering the number of members that satisfy the Building Code verifications before and after the retrofit interventions.

Moreover, it is shown that the introduction of the dissipative devices improves the torsional behavior of the buildings, by increasing their torsional stiffness, and it can eliminate the problem of soft stories.

\section{Modeling and Analysis of Existing Buildings}

\subsection{Verifications of the Structural Elements}

In the Italian Building Code [14] the procedures for the evaluation and verification of existing buildings, which are different from those for new buildings, as well as types of interventions, are provided in a specific chapter, which is further and more specifically explained in instructional code Circolare 21 January 2019 [15]. 
The Italian Code defines three levels of knowledge (LC) for existing buildings, which, in order of increasing knowledge, are LC1, LC2 and LC3. The level of knowledge depends on the depth of knowledge of the structure's geometry, the construction details, the mechanical properties of the materials, and the connections between elements. For every level of knowledge, a corresponding Confidence Factor (FC), greater than one, is defined to reduce the values of the mechanical properties of the materials.

All the structural members must be verified for two different types of mechanisms: ductile and brittle ones. As defined in the instructional code [15], ductile members and mechanisms are beams, columns, and walls subjected to moment with or without axial force, while brittle mechanisms are those involving shear.

The first step of the structural analysis of an existing RC building is the identification of the average strengths of the concrete and reinforcing steel. These strengths can be determined through destructive and non-destructive tests and, if available, from the building design data.

For verifications of ductile mechanisms, concrete and steel strengths are calculated by dividing the average strength by the Confidence Factor, FC. For verifications of brittle mechanisms, the strengths are calculated by dividing the average strength by FC and also by the partial safety factor of the material $\left(\gamma_{m}\right)$, which is equal to 1.5 for concrete and 1.15 for steel [14].

The ductile behavior of beams is verified checking that Equation (1):

$$
M_{R d} \geq M_{E d}
$$

where $M_{E d}$ is the acting moment and $M_{R d}$ the resisting (yield) moment.

For columns converging on the same beam-column joint, the overall bending capacity of the columns, $\sum M_{c, R d}$, must be greater than the overall bending capacity of the beams, $\sum M_{b, R d}$, amplified by the confidence factor, in accordance with the formula, Equation (2):

$$
\sum M_{c, R d} \geq \mathrm{FC} \cdot \sum M_{b, R d}
$$

where $M_{c, R d}$ is calculated for the axial stress levels present in the column due to the seismic combinations of actions.

Regarding the brittle mechanisms, the verification is performed by comparing shear force with shear strength of the members. Considering beams and columns, the shear force is calculated in two different ways. If acting moments at the end sections of the member are lower than the respective yield moments, the shear force is derived from the results of the FEM analysis.

On the contrary, if the acting moments calculated from the analysis are greater than the yield moments, shear force is calculated by considering the beam subjected to the yield moments amplified by FC at the ends and to the gravitational loads of the seismic combination along the beam length.

The shear force $V$ has to be compared to the shear strength, $V_{R d}$, which for cyclic loads, such as seismic loads, is calculated using the following equation [15]. The equation considers not only the three contributions due to axial force, concrete, and steel, but also the interaction with the flexural rotation of the element as function of the plastic ductility demand, $\mu_{\Delta, p l}$, Equation (3):

$$
\begin{gathered}
\quad=\frac{1}{\gamma_{\text {el }}}\left[\frac{h-x}{2 L_{v}} \min \left(N ; 0.55 A_{c} f_{c}\right)\right. \\
\left.+\left(1-0.05 \min \left(5 ; \mu_{\Delta, p l}\right)\right)\left[0.16 \max \left(0.5 ; 100 \rho_{t o t}\right)\left(1-0.16 \min \left(5 ; \frac{L_{v}}{h}\right)\right) \sqrt{f_{c}} A_{c}+V_{W}\right]\right]
\end{gathered}
$$

where $\gamma_{e l}$ is equal to $1.15, h$ is the depth of cross-section, $x$ is the compression zone depth, $N$ is the compressive axial force, $L_{V}$ is the shear span obtained by dividing the acting moment by the acting shear, $A_{c}$ is the cross-section area, $f_{c}$ is the concrete compressive strength, $\rho_{\text {tot }}$ is the total longitudinal reinforcement ratio, and $V_{W}$ is the contribution of transverse reinforcement to shear strength. $V_{W}$ is calculated as $V_{W}=\rho_{s x} b_{w} z f_{y w}$, where $\rho_{s x}$ is the transverse reinforcement ratio, $\mathrm{z}$ is the the internal level arm, $f_{y w}$ is the stirrup yield strength. $\mu_{\Delta, p l}$ is the plastic part of ductility demand equal to 
$\mu_{\Delta, p l}=\mu_{\Delta}-1$, where $\mu_{\Delta}$ is calculated as the maximum chord rotation at the considered seismic action, $\theta_{m}$, normalized to the chord rotation at yielding, $\theta_{y}$.

The maximum chord rotation is assumed equal to Equation (4):

$$
\theta_{m}=\frac{1}{\gamma_{e l}} \cdot 0.016 \cdot(0.3)^{v} \cdot\left[\frac{\max \left(0.01 ; w^{\prime}\right)}{\max (0.01 ; w)} \cdot f_{c}\right]^{0.225} \cdot\left(\frac{L_{v}}{h}\right)^{0.35} \cdot 25^{\left(\alpha \cdot \rho_{s x} \cdot \frac{f_{y w}}{f_{c}}\right)} \cdot\left(1.25^{100 \cdot \rho_{d}}\right)
$$

where $\gamma_{e l}$ is equal to 1.5 for primary seismic elements and 1 for secondary seismic elements, $v$ is the normalized axial force with respect to the concrete area multiplied by the concrete strength, $w$ and $w^{\prime}$ are the mechanical reinforcement ratio of the tension and compression longitudinal reinforcement, respectively, and $\rho_{d}$ is the percentage of any diagonal reinforcements.

The confinement effectiveness factor, $\alpha$, is given by the following Equation (5):

$$
\alpha=\left(1-\frac{s_{h}}{2 b_{0}}\right)\left(1-\frac{s_{h}}{2 h_{0}}\right)\left(1-\frac{\sum b_{i}^{2}}{6 h_{0} b_{0}}\right)
$$

where $s_{h}$ is the distance between the stirrups in the critical area, $b_{0}$ and $h_{0}$ are the dimensions of the confined core, and $b_{i}$ are the distances of the longitudinal bars held by tie rods or stirrups present on the perimeter.

The chord rotation at yielding is obtained using the following expression, Equation (6):

$$
\theta_{y}=\varphi_{y} \frac{L_{v}}{3}+0.0013\left(1+1.5 \frac{h}{L_{v}}\right)+0.13 \cdot \varphi_{y} \frac{d_{b} \cdot f_{y}}{\sqrt{f_{c}}}
$$

where $\varphi_{y}$ is the yield curvature of the section, $d_{b}$ is the mean diameter of the tension reinforcement, $f_{y}$ is the steel yield strength divided by FC, and $f_{c}$ is the concrete strength divided by FC.

Equation (3) is used when $\mu_{\Delta, p l}>3$, while for $\mu_{\Delta, p l}<1$, the following equation is used, Equation (7):

$$
V_{R d}=\max \left\{\left[0.18 \cdot k \cdot \frac{\left(100 \cdot \rho_{l} \cdot f_{c k}\right)^{\frac{1}{3}}}{\gamma_{c}}+0.15 \cdot \sigma_{c p}\right] b_{w} \cdot d ;\left(v_{\min }+0.15 \cdot \sigma_{c p}\right) b_{w} \cdot d\right\}
$$

For $1 \leq \mu_{\Delta, p l} \leq 3$, the shear strength is obtained by interpolating between the value given by Equation (7) and the value given by Equation (3) for $\mu_{\Delta, p l}=3$.

Regarding the parameters of the seismic analysis, for both of the study cases presented herein, the nominal design life, $V_{N}$, representing the number of years in which the structure is to be used for its purposes, is assumed to be 50 years, which is typical for housing. The coefficient of use, $C_{U}$, related to the importance of the building, is assumed equal to 1 , which is the value normally adopted for private buildings. The reference time period for seismic action, $V_{R}$, is obtained from $C_{U} \cdot V_{N}$, hence it is equal to 50 years. The topographic category is T1 (flat surface), and the soil is B-type (coarse-grained soil).

Based on the probability of the seismic action to be exceeded over the time period, $V_{R}$, the Italian Building Code [14] establishes four reference seismic levels, namely, Frequent Design Earthquake (FDE, probability of $81 \%$ ), Serviceability Design Earthquake (SDE, probability of 50\%), Basic Design Earthquake (BDE, probability of 10\%) and Maximum Considered Earthquake (MCE, probability of $5 \%)$.

\subsection{Modeling of the Case Studies}

The two buildings presented herein as case studies are modeled using the commercial software for structural analysis SAP2000. For both of them, beams and columns are modeled through frame elements. Walls are modeled with thick shell elements to consider in-plane and out-of-plane behavior. As prescribed in [14], cracking that arises in the structural members under the applied loads must be taken into account. This can be done by reducing the stiffness of the members. According to [14], 
the flexural and shear stiffnesses of cracked concrete members can be reduced by up to $50 \%$ of the stiffnesses of the corresponding non-cracked members. In the models of the two case studies, the elastic modulus of the concrete is reduced by $50 \%$ for beams, while it is reduced by $30 \%$ for columns due to the presence of axial force on columns, which limits the depth of the cracks.

Floors of building A are $23.5 \mathrm{~cm}$ height and are made by a $3 \mathrm{~cm}$ thick upper RC slab and RC joists with height of $20.5 \mathrm{~cm}$ spaced of $25 \mathrm{~cm}$. Between the joists, lightening elements made of traditional ceiling bricks are put. The same floor type is used in building B. According to [14], a floor can be considered as rigid diaphragm only if the thickness of its slab is at least $4 \mathrm{~cm}$. For this reason, the floors of the considered buildings are not modeled as rigid diaphragms, but as thick shells having the same thickness as that of the slab.

In the Finite Element (FE) models, infill masonry walls are represented to take account of the stiffness and strength they give to the building. As regards the modeling of infill walls, the literature contains several schematizations with one or more compressive struts differently arranged [16-21]. This research work employs the schematization having an offset with respect to the top beam-column joint [17], as shown in Figure 1a.

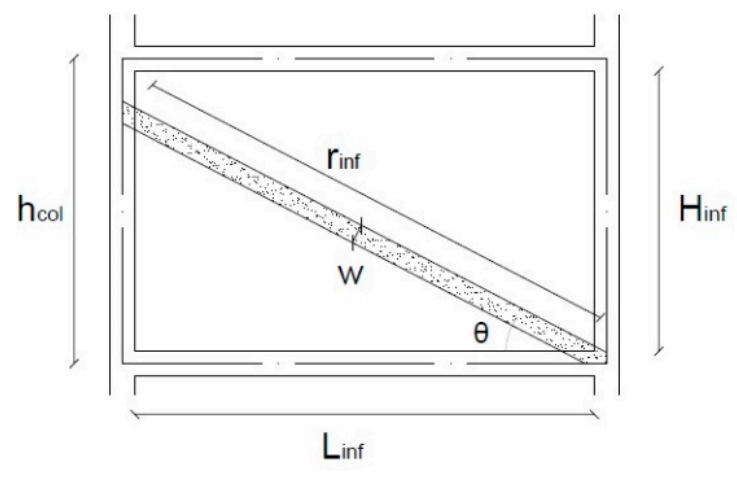

(a)

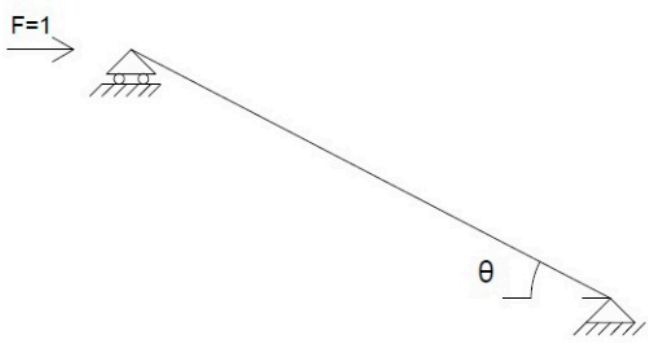

(b)

Figure 1. Infill wall: (a) schematization and (b) static scheme to determine the equivalent stiffness of the infill walls.

The following equation proposed by Mainstone [22] is used to calculate the equivalent strut width, Equation (8):

$$
w=0.175 \cdot\left(\lambda \cdot h_{c o l}\right)^{-0.4} \cdot r_{\text {inf }}
$$

where $r_{\text {inf }}$ is the strut length and $\lambda$ is a dimensionless parameter that takes into account the effect of relative stiffness of the masonry panel to the frame, given by Equation (9):

$$
\lambda=\sqrt[4]{\frac{E_{w} \cdot t_{i n f} \cdot \sin (2 \theta)}{4 \cdot E_{f} \cdot I_{c o l} \cdot h_{i n f}}}
$$

with $E_{w}$ the masonry elastic modulus, $t_{\text {inf }}$ the thickness of the equivalent strut, $\theta$ the inclination angle of the strut with respect to the horizontal direction, $h_{\text {inf }}$ the height of the masonry wall, and $E_{f}$ and $I_{c o l}$ the elastic modulus and the moment of inertia of the column, respectively. Angle $\theta$ is calculated as Equation (10):

$$
\theta=\arctan \left(\frac{H_{\text {inf }}}{L_{\text {inf }}}\right)
$$

where $H_{\text {inf }}$ and $L_{\text {inf }}$ are the lengths of the strut vertical and horizontal projections, respectively.

Diagonal struts are modeled with the SAP2000 non-linear link (Nlink) element "gap", which represents elements offering resisting only in compression. 
The axial stiffness $k$ assigned to the Nlink is calculated by subjecting the diagonal strut to a unitary point load, as shown in Figure 1b. The elastic modulus of the diagonal is assumed equal to $2700 \mathrm{MPa}$, as proposed by [14] for existing walls. Using the calculated displacement $\delta$ of the strut top joint, the axial stiffness is given by Equation (11):

$$
k=\frac{F}{\delta \cdot \cos \theta}
$$

The method of Fast Non-linear Analysis (FNA) is used to analyze the structures of the case studies. This is a modal analysis method, implemented by SAP2000, designed to be used for structural systems which are primarily linear elastic, but which have a limited number of predefined nonlinear elements only. FNA is well-suited for time-history analysis, which is the analysis used in the two case studies, because of its computational efficient formulation. FNA formulation's efficiency is due to the separation of the non-linear-objects vector from the elastic stiffness matrix and the damped equations of motions. At each time increment, forces within the non-linear-objects vector are resolved through an iterative process, while the uncoupled modal equations are solved exactly. This allows the formulation to rapidly converge to the equilibrium solution. Regarding the considered case studies, in the as-built structures the only non-linear members are the infill walls' equivalent struts, while in the retrofitted structures, the only non-linear members are the dissipative braces. Hence, FNA is a suitable analysis method for the case studies.

In the FNA, the modal damping does not depend on the structural stiffness, but only on the properties of the structural vibrational modes. Since the structural vibrational modes do not change during the FNA, the modal damping coefficients $c_{n}$ associated to the $\mathrm{n}_{\text {th }}$ mode remain constant throughout the analysis, even when the structural stiffness changes. Thus, to define the modal damping it is sufficient to specify the damping ratios $\xi_{n}$ for each mode.

For the case studies, the modal damping has been defined by assigning a constant value of the modal damping ratio to all vibration modes. In particular, for the analysis of the existing buildings $\xi_{n}=0.05$ has been assumed, while for the retrofitted structures $\xi_{n}=0.02$ has been assumed.

To perform the FNA, firstly only permanent and variable gravitational loads are applied to the buildings' models by means of a ramp function. Starting from the deformed state of the structure due to these loads, a seismic load is applied, by means of accelerograms. The accelerograms are obtained from a SIMulation of earthQuaKE ground motion software (SIMQKE, prof. Piero Gelfi, Brescia, Italy). According to [14], the accelerogram compatibility with the design response spectrum occurs if the spectral ordinates of the elastic response spectrum obtained from the accelerogram are not $10 \%$ smaller than the corresponding ordinates of the design spectrum within the greater interval between the $0.15 \mathrm{~s}-2 \mathrm{~s}$ and $0.15 \mathrm{~s}-2 \mathrm{~T}$, where $\mathrm{T}$ is the fundamental period of the structure. The fundamental period of building A is $0.67 \mathrm{~s}$, as shown in Table 1.

Table 1. Modal parameters of building A.

\begin{tabular}{ccccc}
\hline \multirow{2}{*}{ Vibration Mode } & Period & \multicolumn{3}{c}{ Modal Participating Mass Ratios } \\
\cline { 2 - 5 } & $\mathbf{( s )}$ & $\mathbf{U x}$ & $\mathbf{U y}$ & $\mathbf{R z}$ \\
\hline 1 & 0.67 & 0.00002 & 0.001 & 0.0017 \\
8 & 0.59 & 0.0005 & 0.10 & 0.62 \\
10 & 0.46 & 0.02 & 0.60 & 0.14 \\
12 & 0.28 & 0.71 & 0.02 & 0.0007 \\
\hline
\end{tabular}

Figure 2 illustrates the elastic response spectrum obtained from one of the accelerograms used in the analysis of building A, overlaid on the design elastic spectrum in the interval $0.15 \mathrm{~s}-4 \mathrm{~s}$. 


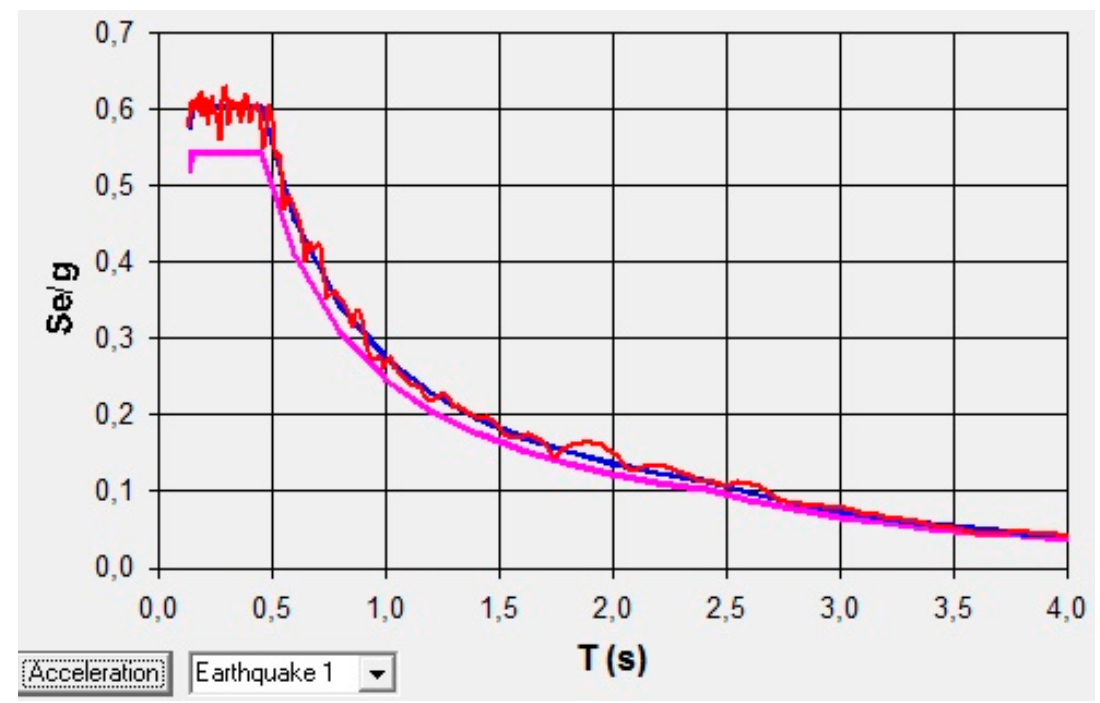

Figure 2. Compatibility verification of one of the accelerograms used.

From Figure 2 it can be seen that the red line, representing the spectral ordinates obtained from the accelerogram, is always above the violet one, representing the design spectrum with spectral ordinates reduced by $10 \%$. Similar results are obtained for the other accelerograms used. It follows that the accelerogram is compatible with the design response spectrum defined by [14].

As prescribed by [14] for the case of non-dissipative structure, for the design spectrum it is possible to use a behavior factor between 1 and 1.5. In both case studies, the value of 1 is assumed. Every accelerogram has a total duration of $30 \mathrm{~s}$. Three groups made by two artificial accelerograms, one in the $\mathrm{X}$ and one in the $\mathrm{Y}$ direction, are considered to represent the seismic action, according to [14]. The most unfavorable effects obtained from the three groups of accelerograms are used for the verifications the structures.

\section{First Case Study-Building A}

\subsection{Geometrical and Structural Characteristics of the Building}

The first case study, building A, whose plan and elevation are shown in Figure 3, is an RC residential building in Udine, Italy, designed and built between 1963 and 1966, in accordance with the provisions of the first Italian Building Code [23].

The building is 70-m long and 23-m wide. Dotted lines in Figure 3a represent the presence of two technical joints, each made of elastomeric material and having a width of $4 \mathrm{~cm}$. These two joints divide the building in three blocks. Each block is composed of two units, which are in opposite position with respect to the central stairwell.

Considering units 2 and 3, the maximum relative displacement in approach between them under seismic action occurs on the fourth floor and it is equal to $2.9 \mathrm{~cm}$. Considering units 4 and 5, the maximum relative displacement in approach between them occurs on the fourth floor and it is equal to $3.2 \mathrm{~cm}$.

In both cases the relative displacement of the two blocks is smaller than the width of the technical joint. Moreover, being that the joints are made of elastomeric material, their rigidity is assumed negligible. Hence, the blocks are not likely to interact during the seismic motion. For this reason, the building can be divided into three independent blocks.

According to [14], each block is irregular both in plan and along the height. The irregularity in plan (Figure 3a) is due to the dispersed layout and the asymmetrical distribution of mass and stiffness with respect to two orthogonal directions of the block. The irregularity along the height (Figure 3b) is due to the different heights of the units and the staggered floors. 
The two lateral housing units (no. 1 and 6) have three floors; the others have four floors. In all of the units the under-roof floor is impracticable, and the inter-story height of units is about $2.8 \mathrm{~m}$, except for the first floor of units no. 1, 4, and 6, whose height is $4 \mathrm{~m}$. On the ground floor of units no. 1,4 , and 6 , the RC frame is not filled in by masonry walls, while the other three units have RC ground frames filled by masonry walls up to about $30 \mathrm{~cm}$ from the first floor. In this $30 \mathrm{~cm}$ there is a continuous strip window.

Building A's vertical structures consist of columns, all with a section of $20 \times 60 \mathrm{~cm}$, with the larger side parallel to the y axis (Figure 3a), and walls only in correspondence with stairwells. All walls are 20-cm thick: the ones in X direction have length $520 \mathrm{~cm}$ and the ones in Y direction have length $315 \mathrm{~cm}$. The longitudinal reinforcement of central columns (columns like C2, C3 and C6 in Figure 3a) is made by $4 \Phi 16$ at corners along the entire height. The reinforcement of external columns (columns like C1, C4 and C5) is composed of two layers per story, with layers comprising $4 \Phi 16$ parallel to the two larger sides of the section in the lower three stories, and two layers of $3 \Phi 16$ in the top story where there are short columns that bear the roof. The transverse reinforcement of the columns consists of $\Phi 6$ every $10 \mathrm{~cm}$.

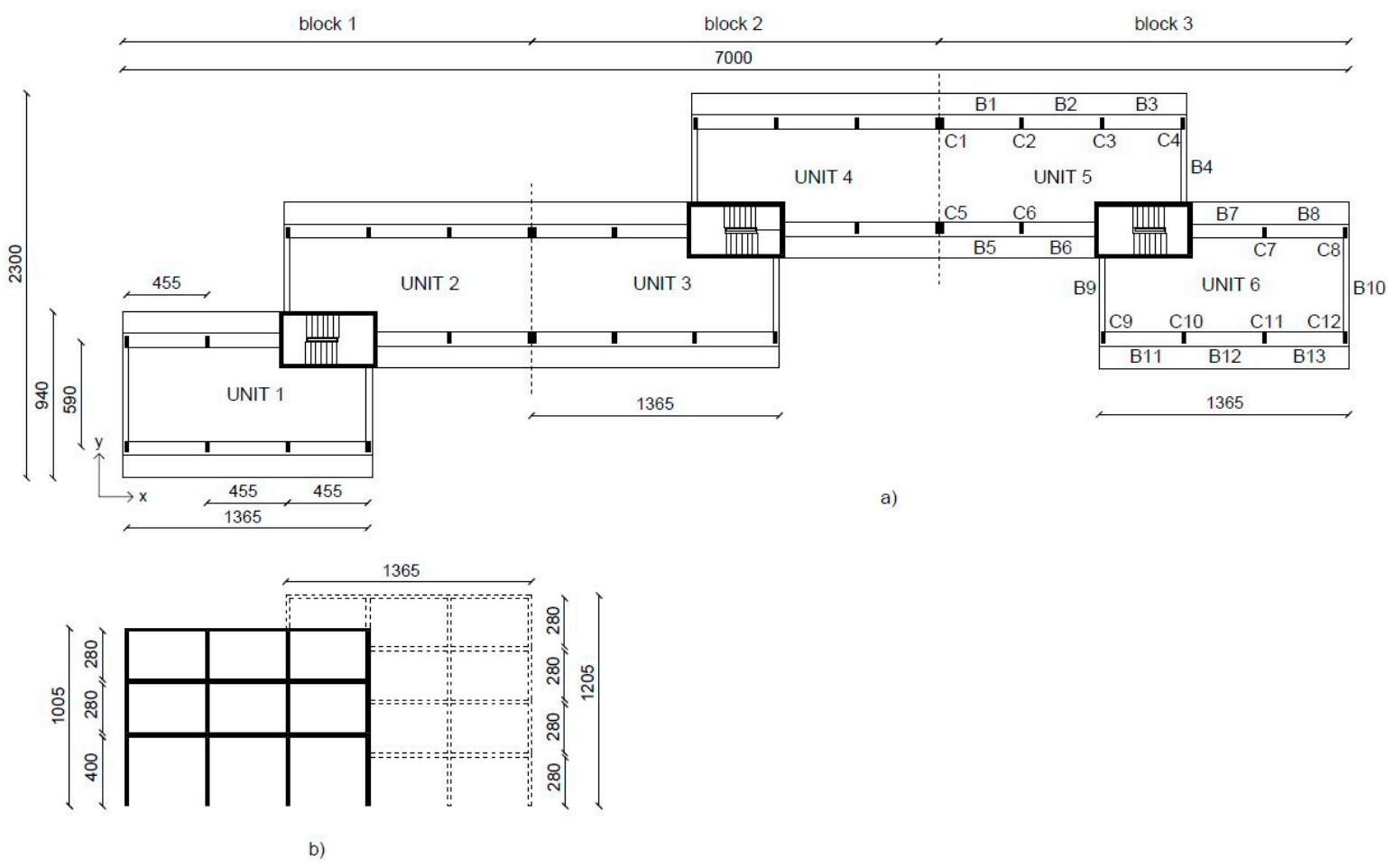

Figure 3. Building A: (a) plan of the first floor and (b) elevation of block 1.

Primary beams, oriented in $X$ direction, have a section of $80 \times 15 \mathrm{~cm}^{2}$. Secondary beams, oriented parallel to the $Y$ direction, are present only in the exterior sides of the building and have a section of $33 \times 23.5 \mathrm{~cm}^{2}$. All under-roof floors have beams parallel to the $X$ direction, with a section of $80 \times 15 \mathrm{~cm}^{2}$, and beams parallel to the $y$ direction with a section of $20 \times 15 \mathrm{~cm}^{2}$. The longitudinal reinforcement of all beams is made by $\Phi 16$. The transverse reinforcement for beams in the $X$ direction consists of $\Phi 8$ every $7 \mathrm{~cm}$ close to the ends and every $25 \mathrm{~cm}$ in the middle, while beams parallel to the $\mathrm{Y}$ direction are reinforced by $\Phi 6$ every $25 \mathrm{~cm}$.

Floors are made of precast RC joists, oriented parallel to the $\mathrm{Y}$ direction and having a depth of $20.5 \mathrm{~cm}$ and an interaxle spacing of $25 \mathrm{~cm}$, completed with clay bricks and a cast-in-place concrete slab 3-cm thick. The under-roof floor is of the same type with the only difference being the joint depth, which is equal to $15.5 \mathrm{~cm}$. In addition, the structure of the roof is similar, with a joint depth of $19.5 \mathrm{~cm}$. 
Foundations are composed of inverse T-shape RC beams, which connect the columns in the $\mathrm{Y}$ direction, and $\mathrm{RC}$ curbs in the $\mathrm{X}$ direction.

The characteristics of the materials are defined on the basis of available documentation. The concrete characteristic cylindrical compressive strength is equal to $25 \mathrm{MPa}$. The concrete average strength can be calculated as $25+8=33 \mathrm{MPa}$. Reinforcing bars are of Aq50 type, hence, according to [24], have a characteristic yield strength of $264.9 \mathrm{MPa}$. According to [14], the yield average strength of steel can be calculated as $264.9 \times 1.125=298 \mathrm{MPa}$.

For the considered case study, a level of knowledge LC2 is assumed, to which a confidence factor $\mathrm{FC}=1.2$ corresponds [14]. Consequently, the concrete design compressive strength to be used for ductile mechanism verifications is $33 / 1.2=27.5 \mathrm{MPa}$, and that for brittle mechanism verifications is $33 /(1.2 \times 1.5)=18.3 \mathrm{MPa}$. The steel design yield strength for ductile mechanism verifications is $298 / 1.2=248.3 \mathrm{MPa}$, and that for brittle mechanism verifications is $298 /(1.2 \times 1.15)=215.9 \mathrm{MPa}$. To take account of cracking, a reduced concrete elastic modulus equal to 22,033 MPa for beams and 15,738 MPa for columns is considered.

Gravity loads due to the floor weight are represented by a dead load of $4 \mathrm{kN} / \mathrm{m}^{2}$ on habitable stories, $2.35 \mathrm{kN} / \mathrm{m}^{2}$ on the under-roof story, and $2.70 \mathrm{kN} / \mathrm{m}^{2}$ for the roof. The weight of the infill perimeter walls is considered assuming a linearly distributed load of $9.97 \mathrm{kN} / \mathrm{m}$ acting on the beams below. Live loads of $2 \mathrm{kN} / \mathrm{m}^{2}$ are applied on all habitable stories, as well as $4 \mathrm{kN} / \mathrm{m}^{2}$ on balconies and staircases, $0.5 \mathrm{kN} / \mathrm{m}^{2}$ on under-roof floors, and $1.2 \mathrm{kN} / \mathrm{m}^{2}$ on the horizontal projection of the roof, due to the snow.

Since the three two-unit blocks of which the building is made are equivalent to each other, an analysis of only the block formed by units 5 and 6 is presented in the following.

\subsection{Results of the Modal and FNA Analyses}

The results of the modal analysis on one building block are summarized in Table 1, where the period of vibration of the main modes are reported together with the corresponding Modal Participating Mass Ratio (MPMR) in the three principal directions of the building. Table 1 shows that modes 8 and 10 are mixed rotationally around the vertical axis $\mathrm{z}$ and translationally along $\mathrm{Y}$ axis. Mode 12 is translational along $\mathrm{X}$.

All the results of the verifications for beams and columns are shown in Figures 4-7, where on the horizontal axis the names of the members are reported, with beams indicated by letter $\mathrm{B}$ and columns by $C$. The letter is followed by an ordinal number, which identifies the position of the member with respect to the building plan, as shown in Figure 3.

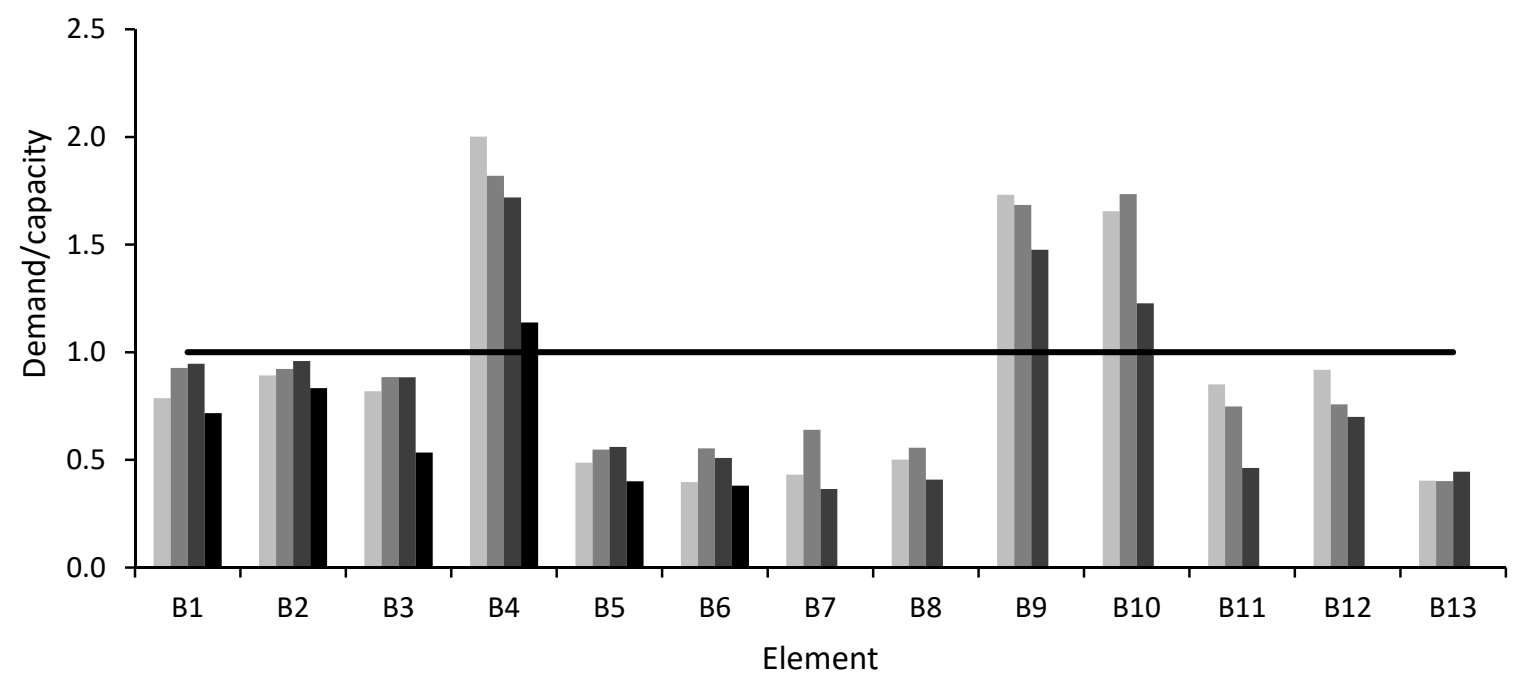

Figure 4. Bending verifications of beams in as-built condition. 


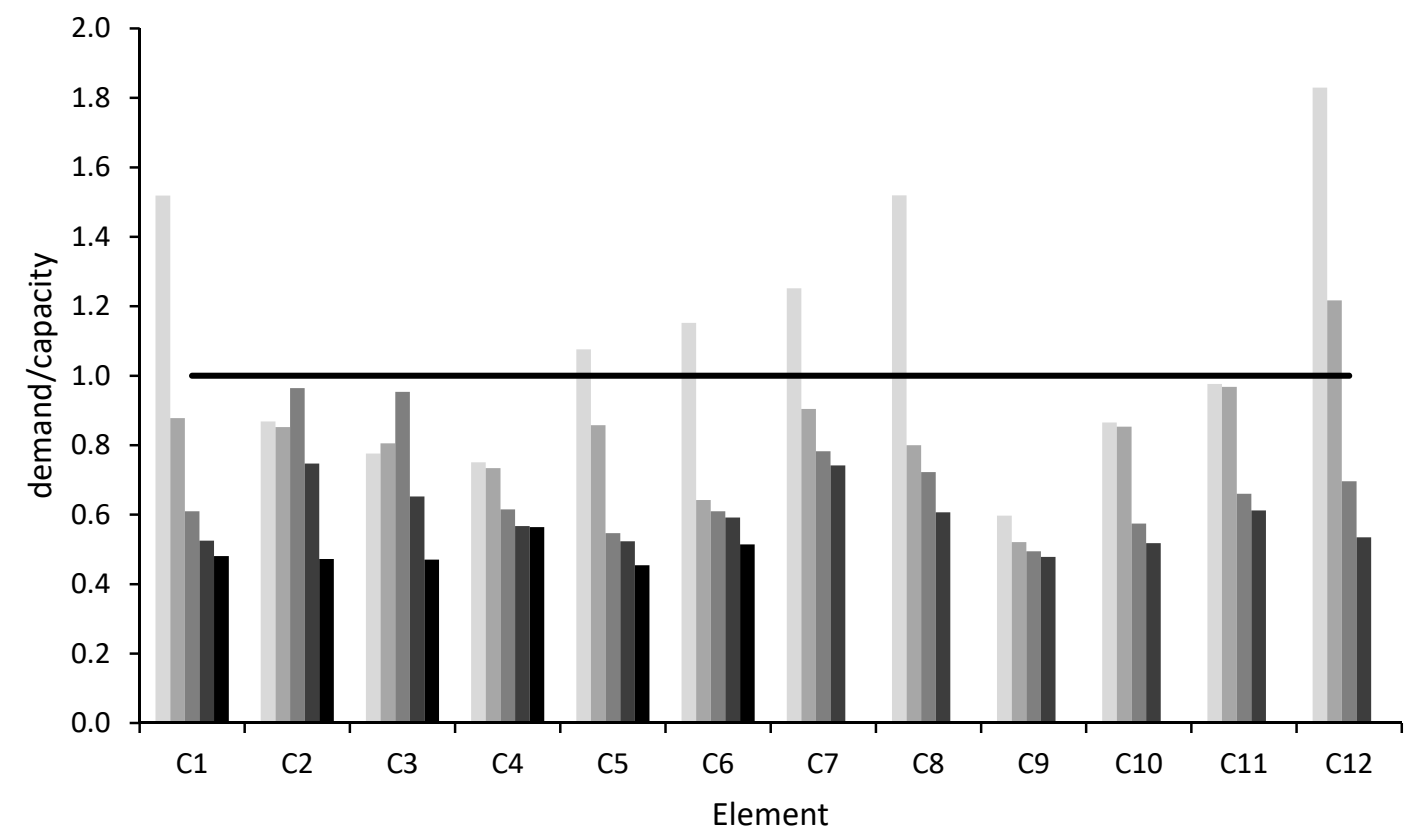

Figure 5. Combined bending and compression verifications of columns in as-built condition.

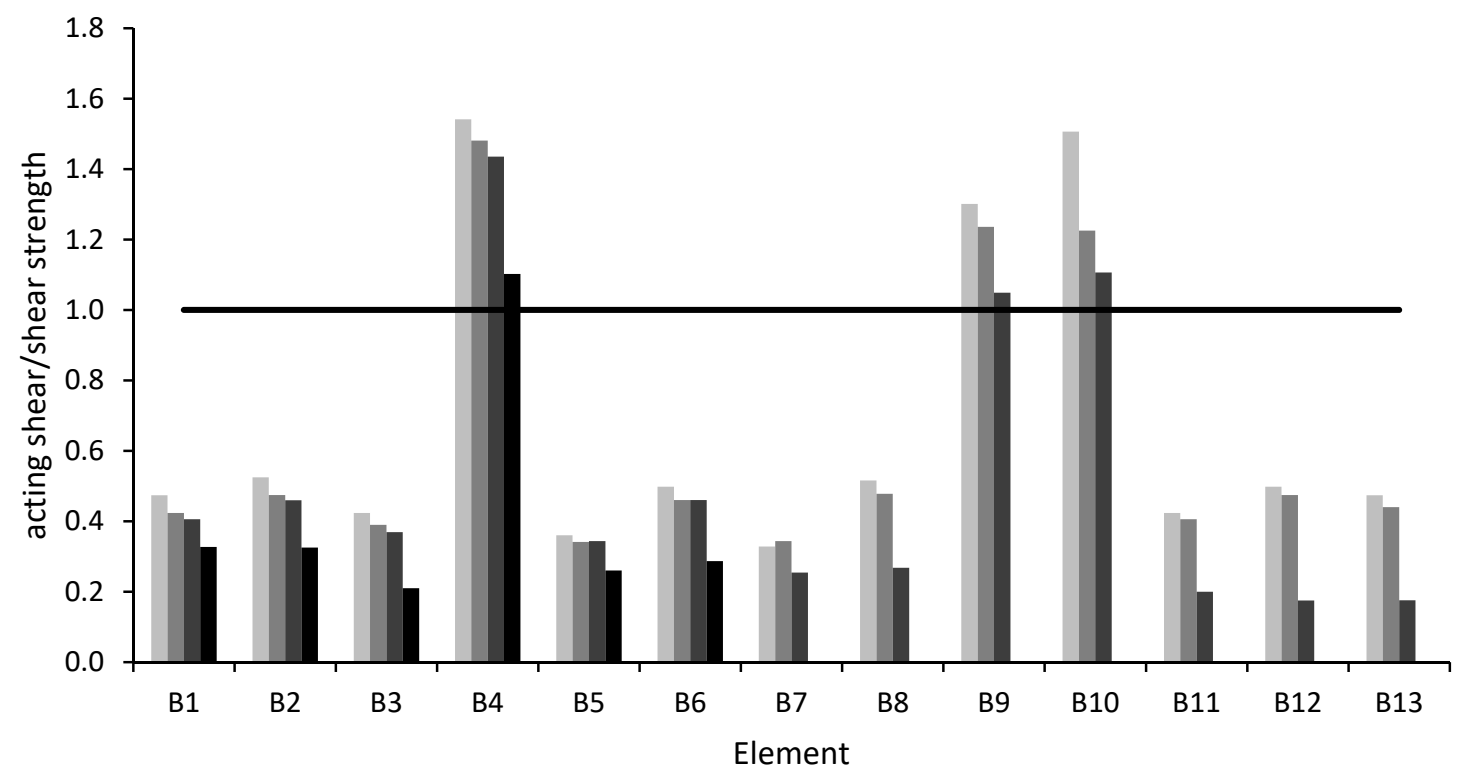

Figure 6. Shear verifications of beams in as-built condition.

In the diagrams of Figures 4-7, for every member, three or four differently colored columns are drawn. These columns indicate the position of the member with respect to the stories of the building, where the lighter column corresponds to the lower level, while the gradually darker columns indicate higher and higher levels.

For the verification of ductile mechanisms, in Figures 4 and 5 the ratio between demand and capacity is represented on the vertical axis. For the verification of brittle mechanisms, in Figures 6 and 7 the ratio between acting shear force and the shear strength is reported. For both types of mechanisms, the verification is satisfied if the ratio is less than 1 ; otherwise it is not satisfied.

Figure 4 shows that all beams in the $x$ direction satisfy ductile mechanism verifications, since the ratio between demand and capacity is lower than 1 in all cases. Secondary beams, in the y direction, do not satisfy this verification, due to the small section and the low amount of steel reinforcement. 
Figure 5 shows that the columns that are more distant from the walls, namely $\mathrm{C} 1, \mathrm{C} 5, \mathrm{C} 8$ and $\mathrm{C} 12$, do not satisfy the ductile verification at the base. Additionally, columns C6 and C7 do not satisfy the ductile verification at the base, because they have less longitudinal reinforcement.

Figure 6 shows that the ratio between shear acting force and shear strength is lower than 1 for all beams in the $\mathrm{X}$ direction (B1-B3, B5-B8 and B11-B13), which have transverse reinforcement spacing equal to $25 \mathrm{~cm}$ in the middle and $7 \mathrm{~cm}$ at the beam ends. Conversely, the ratio is greater than 1 for the beams in the y direction (B4, B9 and B10), which have a constant spacing of $25 \mathrm{~cm}$ everywhere along the beam.

Figure 7 shows that, in unit 6, the acting shear force exceeds the shear strength on the last level, where columns connect the top floor with the roof and have a short length, equal to $1.4 \mathrm{~m}$. In unit 5 this occurs also on the first story, due to the presence, at this level, of infill walls with an opening of about $30 \mathrm{~cm}$ at the top. This configuration induces shear failure due to short column effect.

The joints of the building have no transverse reinforcement for shear resistance. For this reason, none of them satisfy the tensile verification for beam-column joints according to [15]. Furthermore, none of the interior joints satisfy the compressive verification, which is satisfied only for the exterior joints.

Regarding the walls, both ductile and brittle verifications are satisfied. On the basis of the previously described results, it can be said that the building may develop brittle non-dissipative failure mechanisms under seismic action. To improve its behavior a retrofit intervention with the use of dissipative devices is proposed.

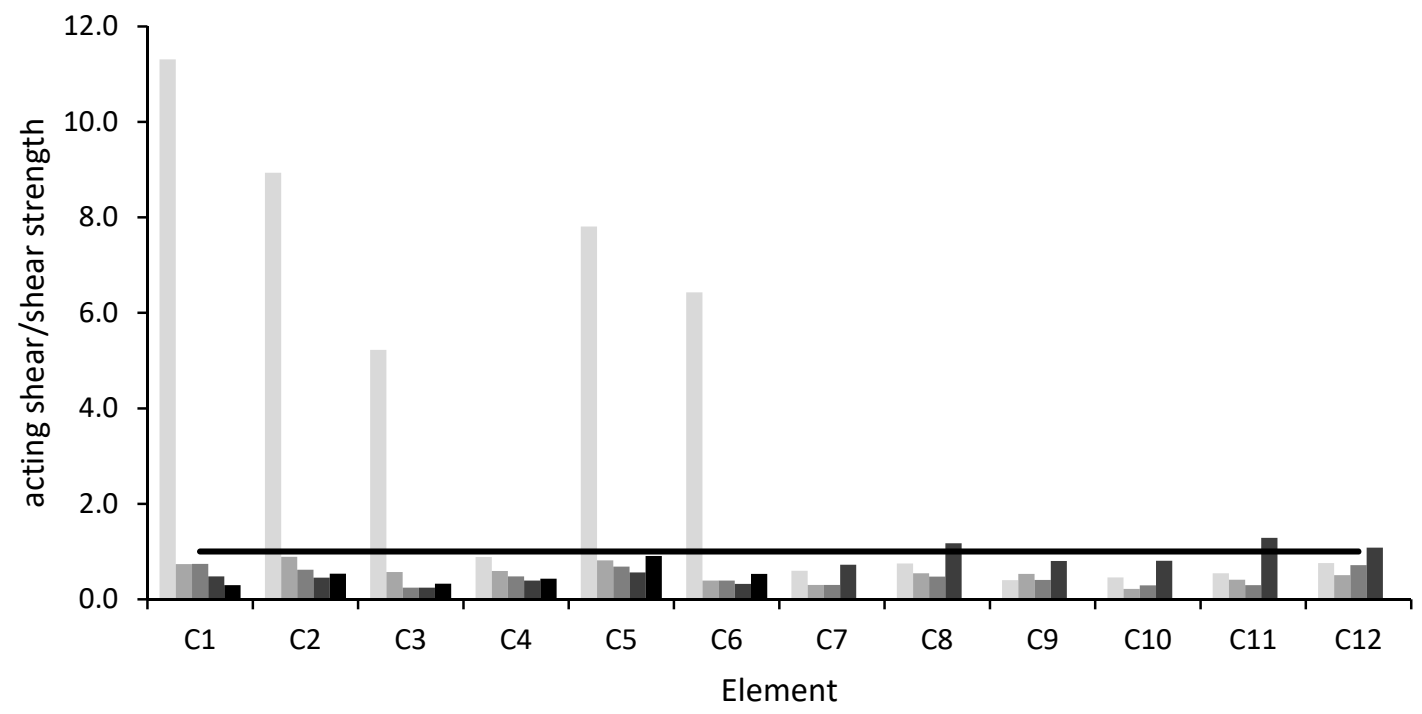

Figure 7. Shear verifications of columns in as-built condition.

\subsection{Retrofit Intervention with BRADs and Effects}

A BRAD $[25,26]$ is a non-linear anti-seismic device whose behavior depends on displacement. The most common configuration of BRADs consists of an internal steel core encased in an external hollow steel profile, filled with concrete. A layer of low friction material is interposed between the steel core and concrete and allows relative axial deformation between the inner core and the external steel profile. This slip surface allows the steel core to deform in the plastic field and, therefore, dissipate energy. Lateral confinement, conferred by the concrete layer and the external steel profile, prevents buckling of the steel core during the compression phase. In this way, it is possible to dissipate energy both during tension and compression phases. BRADs are particularly suitable to be mounted on steel braces for seismic retrofit of steel and RC frame buildings, both new and existing. Their use leads to an improvement in the dissipative capacity of the building, concentrating the dissipation in the devices and, therefore, reducing the actions on the building structural members. The advantages 
of BRADs are evident from the large hysteresis loops, significant stiffness after yielding, and slight strength deterioration under cyclic loading, all of which contribute to a reduction in displacements and good energy dissipation capacity.

In SAP2000, BRADs can be implemented by using the Nlink "Plastic wen", due to the fact that the hysteretic cycles obtained using this Nlink are similar to the ones obtained from experimental tests.

In the catalogue [25] from which the devices have been chosen, each BRAD type is identified by a code of the type $\mathrm{N} / \mathrm{M}-\mathrm{b}$, where $\mathrm{N}$ is the number of the model. As this number increases, there is an increase in the elastic stiffness, the yielding strength and the ultimate strength of the device. The second number, $\mathrm{M}$, represents the sum of the devices' allowed displacements in tension and compression and the letter " $\mathrm{b}$ " means BRAD. Elastic stiffness, yield strength, post yield stiffness ratio and yielding exponent are the parameters required to define the constitutive relationship of the devices.

BRAD choice and position inside the structure have been arranged by a trial and error method. Different in plan and in elevation dispositions, with different BRAD types, were analyzed. It was observed that placing the devices as much as possible near the perimeter gave the best results. Moreover, it was observed that by using different devices with gradually lower stiffness along the elevation, large hysteretic cycles were developed also by the devices in the highest floors. Many of the studied configurations had good results, but the one proposed in the following gave the best results in terms of width of device hysteretic cycles and, consequently, in terms of energy dissipation.

According to the analyses carried out, the authors believe that they have achieved the optimization of the devices. For BRADs of 34/30-b type the elastic stiffness, the yielding strength, the post yield stiffness ratio and the yielding exponent are equal to 194,000 kN/m, $301 \mathrm{kN}, 0.01$ and 1, respectively. The same properties are equal to $156,000 \mathrm{kN} / \mathrm{m}, 239 \mathrm{kN}, 0.01$ and 1, respectively, for BRADs of 27/30-b type, to $115,000 \mathrm{kN} / \mathrm{m}, 178 \mathrm{kN}, 0.01$ and 1, respectively, for BRADs of 21/30-b type, and to 79,000 kN/m, $119 \mathrm{kN}, 0.01$ and 1, respectively, for BRADs of 14/30-b type.

To realize the building retrofit, V-shaped steel braces on which BRADs are mounted are installed as shown in Figure 8.
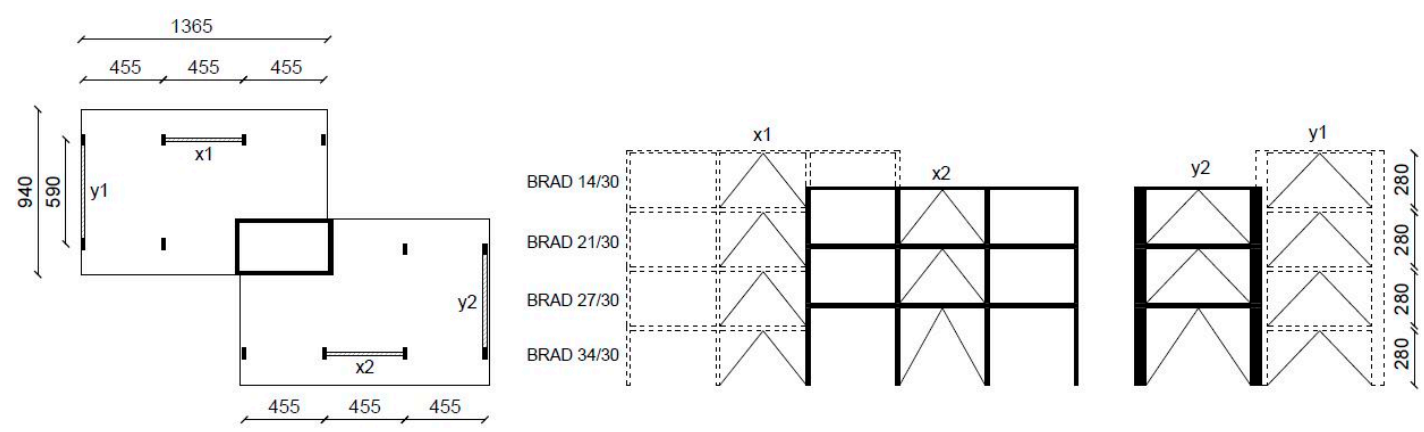

Figure 8. Distribution of dissipative device in plan and elevation.

Considering that the distribution of the total shear force in buildings decreases with the height, and that the building has bays without infill walls on the first level, starting from this level, gradually less rigid devices are used. In particular, BRADs of 34/30-b type are installed on the first story, 27/30-b on the second, 21/30-b on the third and, only in unit 5 , which has a fourth story, $14 / 30-\mathrm{b}$ on the last level. The braces are inserted in both the two main directions of the building to globally increase its resistance. They are placed in the perimeter frames, to increase the torsional stiffness of the building.

After the introduction of the devices in the FE building model, the FNA is performed and the energy dissipated by the devices is evaluated. The graphs representing the energy patterns are plotted in Figure 9. 


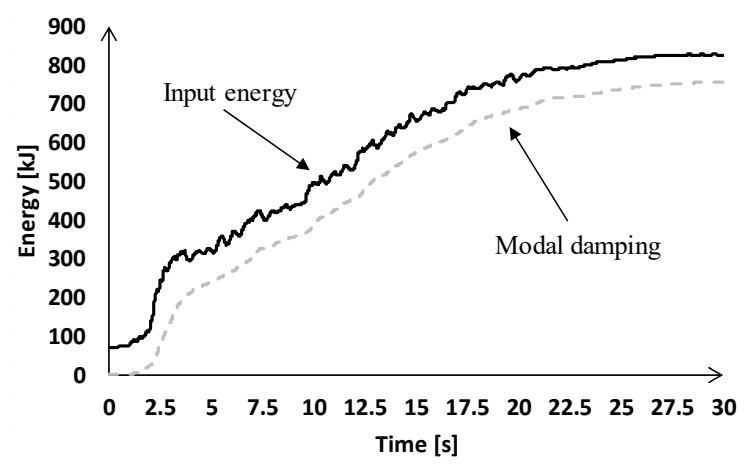

(a)

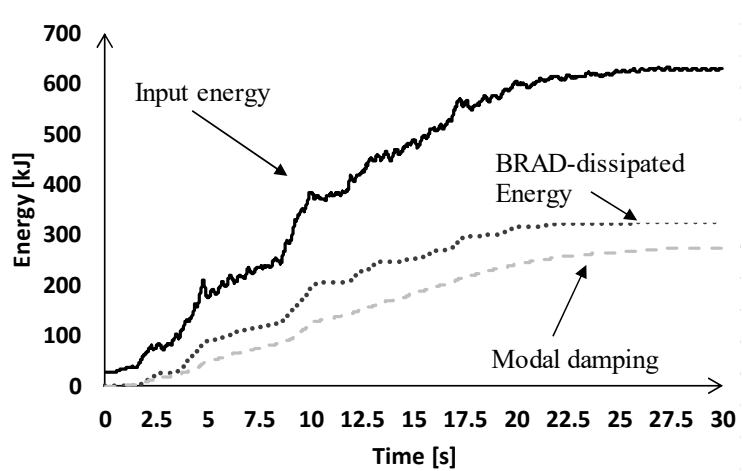

(b)

Figure 9. Energy diagrams for building A in: (a) as-built configuration; (b) after retrofit.

In Figure 9a, the graph relative to the energy dissipated by the as-built construction through modal damping is compared to the total input energy. It is observed that the great part of input energy is dissipated precisely by modal damping, while the remaining small amount is balanced by the kinetic and the elastic energy of the building, not represented in the diagram.

In Figure $9 \mathrm{~b}$, the graph relative to the energy dissipated by the retrofitted building is shown. From this figure it can be seen that, at $t=30$ s, i.e., at the end of the seismic event, more than half of the input energy is dissipated by BRAD devices. For the energy balance it follows that, at the same instant of time, the energy dissipated by the modal damping of the structure is lower than the half of the input energy. Thus, from the comparison between Figure $9 a, b$, it can be observed that the adoption of BRADs leads to a reduction in the energy absorbed by the building structural members, represented by the modal damping energy, and a consequent reduction or elimination of structural damage.

Great reliability of the energy dissipation system is required by the Italian Building Code [14], due to the important role the devices play during a seismic event. In particular, it is required that the devices not break or exhibit damage under the MCE. This is assured by checking the device peak displacement, which, as prescribed by [14], is obtained by the sum two values. The first one is the displacement due to an earthquake with intensity greater than the one used for the BDE, for which the displacement due to the MCE is assumed. The second value is obtained considering the maximum between the residual displacement at the SDE and the displacement corresponding to axial force equal to zero, following the path starting from the point of maximum displacement at the SDE, reduced by $50 \%$. The peak displacement obtained by the sum of these two values must be kept below the device's allowed displacement.

Figure 10 shows the cyclic response of four devices, one for each type used, under the MCE, representing the most stressed ones.

From the diagrams in this figure it is possible to obtain the first value necessary to calculate the peak displacement. For the four devices, the second value is always found to be the residual displacement at the SDE. The peak displacements, obtained as described, for BRAD 34/30-b, 27/30-b, 21/30-b and 14/30-b are, respectively, $3.1 \mathrm{~mm}, 8.7 \mathrm{~mm}, 10.7 \mathrm{~mm}$ and $11.1 \mathrm{~mm}$. All of them are lower than the device's allowed displacement, that is $15 \mathrm{~mm}$.

Having verified that the behavior of the anti-seismic devices is compliant with the code [14], verifications of the structural members are performed. In the as-built configuration, secondary beams and some of the columns at the base do not satisfy ductile verifications. Hence the verifications of only these members of the retrofitted building are shown in Figure 11.

In this figure, the names of the members are reported in the horizontal axis, where beams are indicated with letter B and columns with C. From Figure 11 it can be observed that, thanks to the retrofit intervention, the ratio demand/capacity is always lower than 1. For example, column $\mathrm{C} 1$, which does not satisfy the ductile verification in the as-built condition, after the retrofit intervention 
shows a reduction in the acting bending moment of about $66 \%$ (from $322.2 \mathrm{kN} \cdot \mathrm{m}$ to $108.6 \mathrm{kN} \cdot \mathrm{m}$ ). On average, the reduction in the acting bending moment is of $49 \%$ for beams and $62 \%$ for columns.

The results of brittle verifications only, for members not verified before the introduction of BRADs, are shown in Figure 12.

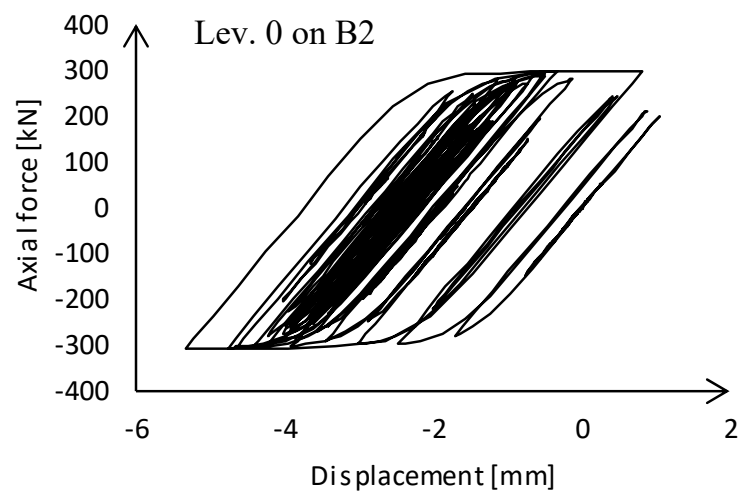

(a)

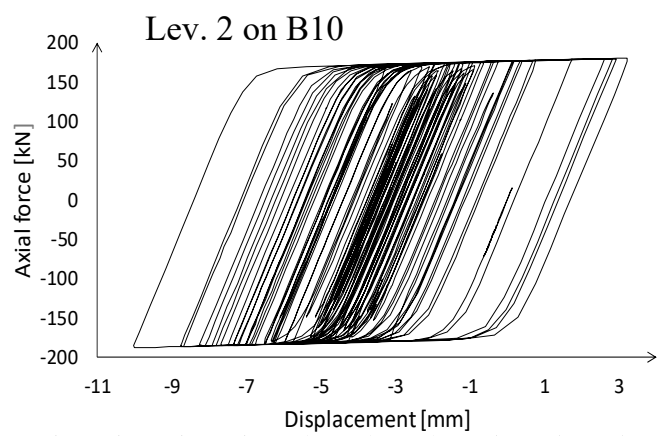

(c)

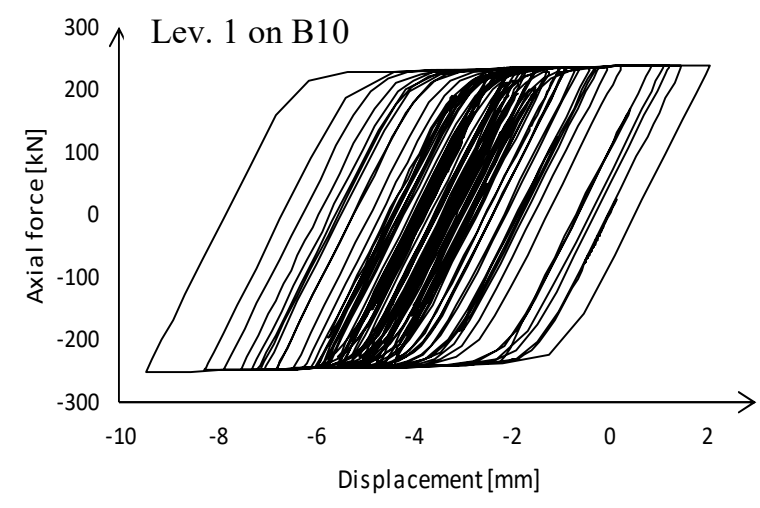

(b)

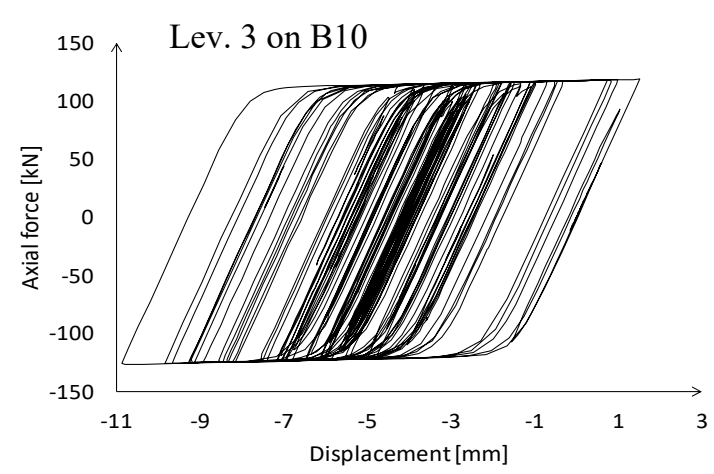

(d)

Figure 10. Cyclic response of different Buckling-Restrained Axial Damper (BRAD) types under an accelerogram of the Maximum Considered Earthquake (MCE): (a) 34/30-b (b) 27/30-b (c) 21/30-b (d) $14 / 30-b$.

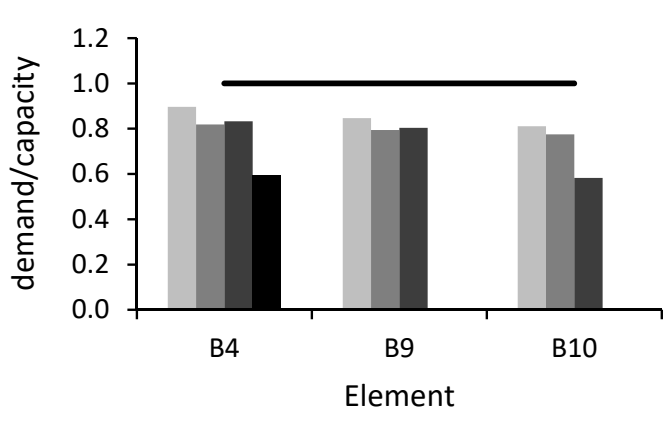

(a)

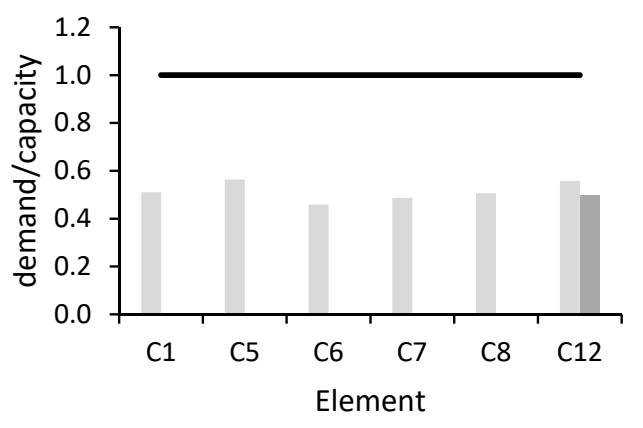

(b)

Figure 11. Ductile verifications after retrofit of: (a) beams and (b) columns. 


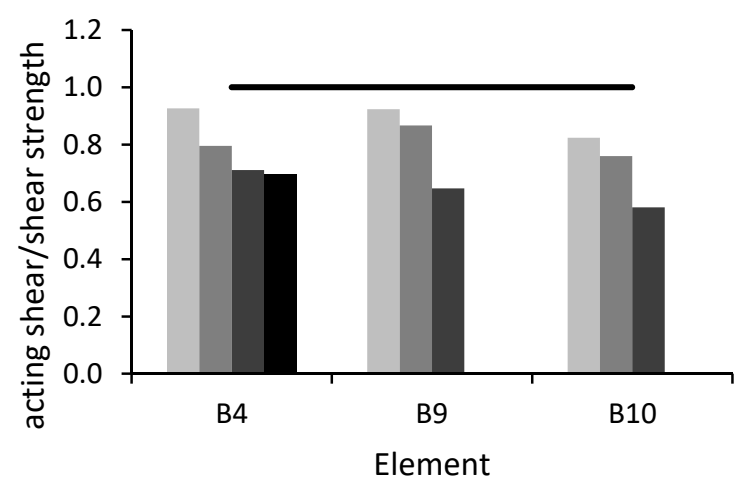

(a)

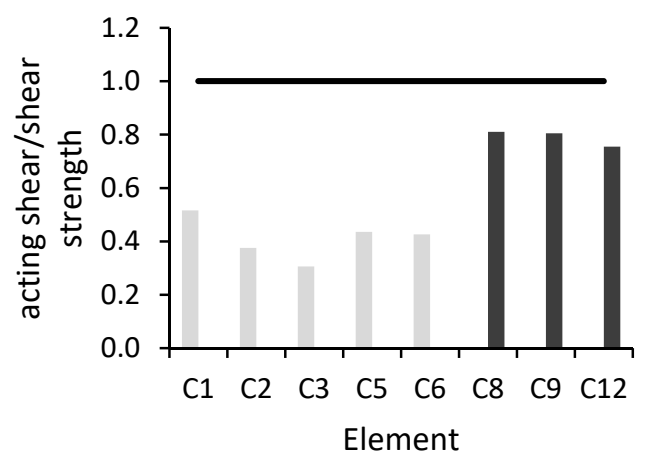

(b)

Figure 12. Shear verifications after retrofit of: (a) beams and (b) columns.

From this figure it can be observed that, thanks to the retrofit intervention, the demand/capacity ratio is always lower than 1 . For example, beam B4, which did not satisfy the shear verification in the as-built condition, after the retrofit intervention shows a reduction in the acting shear of about $57 \%$ (from $23.4 \mathrm{kN}$ to $10.1 \mathrm{kN}$ ). On average, the reduction in the acting shear is of $55 \%$ for beams and $64 \%$ for columns. These results show the great benefits obtained from the use of the dissipative system.

Regarding verification of beam-column joints, many of them are still not verified even after retrofit. Hence, for improving their performance, local strengthening interventions are needed.

Regarding the walls, verifications are already satisfied in the as-built configuration, before the introduction of the dissipative devices.

\subsection{Building Torsional Stiffness}

Torsional stiffness of the building is an important parameter that has to be considered in the design of retrofit interventions. In fact, low torsional stiffness, together with irregularity in plan, may produce additional non-negligible displacements in the columns, especially in those that are placed along the building perimeter. To evaluate if the installation of dissipative braces is able to increase the building torsional stiffness, this parameter is calculated before and after the introduction of BRADs. To calculate the torsional stiffness of the building, the torsional stiffness of each floor has to be determined, and the minimum among the determined stiffnesses has to be considered. The torsional stiffness of each floor is calculated by applying a torsional moment around the z-axis (perpendicular to the floor) and surveying its rotation.

To perform this calculation, since the considered building has slightly staggered floors (Figure $3 \mathrm{~b}$ ) a simplification is introduced by assigning the same diaphragm constraint to the pairs of floors that are closest to each other. Then the torsional moment $M_{\text {tor }}$ around the Z-axis is applied to the center of mass of a diaphragm, while all other diaphragms are embedded. The rotation of the center of mass, $\gamma$, due to this torsional moment, is obtain from the FE model, and the torsional stiffness, $k_{t o r}$, is calculated as Equation (12):

$$
k_{\text {tor }}=\frac{M_{\text {tor }}}{\gamma}
$$

To evaluate the improvement of the torsional stiffness of each building floor due to the presence of BRADs, $k_{t o r}$ is calculated in the same way on the FE model with dissipative devices. Relative results are reported in Table 2. 
Table 2. Comparison of torsional stiffness and deformability of building A before and after retrofitting.

\begin{tabular}{|c|c|c|c|c|c|c|c|c|c|c|}
\hline \multirow[b]{2}{*}{ Level } & \multicolumn{4}{|c|}{ Before Retrofitting } & \multicolumn{4}{|c|}{ After Retrofitting } & \multirow{2}{*}{$\begin{array}{c}k_{t o r} \\
\text { Variation }\end{array}$} & \multirow{2}{*}{$\begin{array}{c}r_{s}^{2} / l_{s}^{2} \\
\text { Variation }\end{array}$} \\
\hline & $\begin{array}{c}k_{t o r} \\
(\mathrm{GN} \cdot \mathrm{m} / \mathrm{rad})\end{array}$ & $\begin{array}{c}k_{f} \\
(\mathrm{GN} / \mathrm{m})\end{array}$ & $\begin{array}{c}r_{s}^{2} \\
\left(\mathrm{~m}^{2} / \mathrm{rad}\right)\end{array}$ & $r_{s}^{2} / l_{s}^{2}$ & $\begin{array}{c}k_{t o r} \\
(\mathrm{GN} \cdot \mathrm{m} / \mathrm{rad})\end{array}$ & $\begin{array}{c}k_{f} \\
(\mathrm{GN} / \mathrm{m})\end{array}$ & $\begin{array}{c}r_{s}^{2} \\
\left(\mathrm{~m}^{2} / \mathrm{rad}\right)\end{array}$ & $r_{s}^{2} / l_{s}^{2}$ & & \\
\hline 1 & 90.91 & 5.30 & 17.15 & 0.28 & 101.32 & 53.22 & 19.04 & 0.31 & $+11.5 \%$ & $+11.0 \%$ \\
\hline 2 & 100.00 & 5.74 & 17.41 & 0.28 & 106.78 & 57.70 & 18.51 & 0.30 & $+6.8 \%$ & $+6.3 \%$ \\
\hline 3 & 66.67 & 4.33 & 15.41 & 0.25 & 71.43 & 43.33 & 16.49 & 0.27 & $+7.1 \%$ & $+7.0 \%$ \\
\hline
\end{tabular}

The introduction of the dissipative devices increases the building torsional stiffness, especially on the first level (ground floor), where an improvement of about $12 \%$ is obtained, while in the other two levels, the increase in torsional stiffness is about $7 \%$.

To assess whether a structure is torsionally deformable, the Italian Building Code [14] prescribes the determination of the minimum of the ratios between $r_{s}^{2}$ and $l_{s}^{2}$, where $r_{s}^{2}=k_{t o r} / k_{f}$ is the ratio between $k_{t o r}$ and the flexural stiffness, $k_{f}$, of each floor, and $l_{s}{ }^{2}$, in cases of a rectangular plan, is equal to $\left(L^{2}+B^{2}\right) / 12$, with $L$ and $B$ the dimensions of the floor in the plan. For building A, considering the floor coinciding with a diaphragm, $l_{s}{ }^{2}=61.9 \mathrm{~m}^{2}$ for all diaphragms. Since $l_{s}{ }^{2}$ is constant, to obtain the minimum ratio $r_{s}^{2} / l_{s}^{2}$, the minimum value of $r_{s}$ has to be considered; hence, the maximum $k_{f}$ has to be calculated. To do this, a unitary point load, $F$, is applied, along one of the building's principal directions, to the center of rigidity of the considered diaphragm, while the other diaphragms are embedded. This results in a translational displacement, $d$, of the floor without torsional effect. The flexural stiffness, is then obtained from Equation (13):

$$
k_{f}=\frac{F_{y}}{d}
$$

The maximum flexural stiffness of the building is gained in the y direction. The corresponding results are shown in Table 2, where it can be seen that the ratios $r_{s}^{2} / l_{s}^{2}$ are higher than 1.0 for all levels. This is the limit above which a building can be considered not torsionally deformable according to [14]. For this reason, from the point of view of torsional deformability, the behavior of building A before retrofitting cannot be regarded as satisfactory.

There is still a benefit brought by the use of BRADs, because, after retrofit, on the first level $r_{s}^{2} / l_{s}^{2}$ increases by about $11 \%$, and on the other two levels it increases by more than $6 \%$.

\section{Second Case Study-Building B}

\subsection{Geometrical and Structural Characteristics of the Building}

The second case study, building B (Figure 13), is another residential building, situated in Udine, Italy, designed in 1966 in accordance with [23].

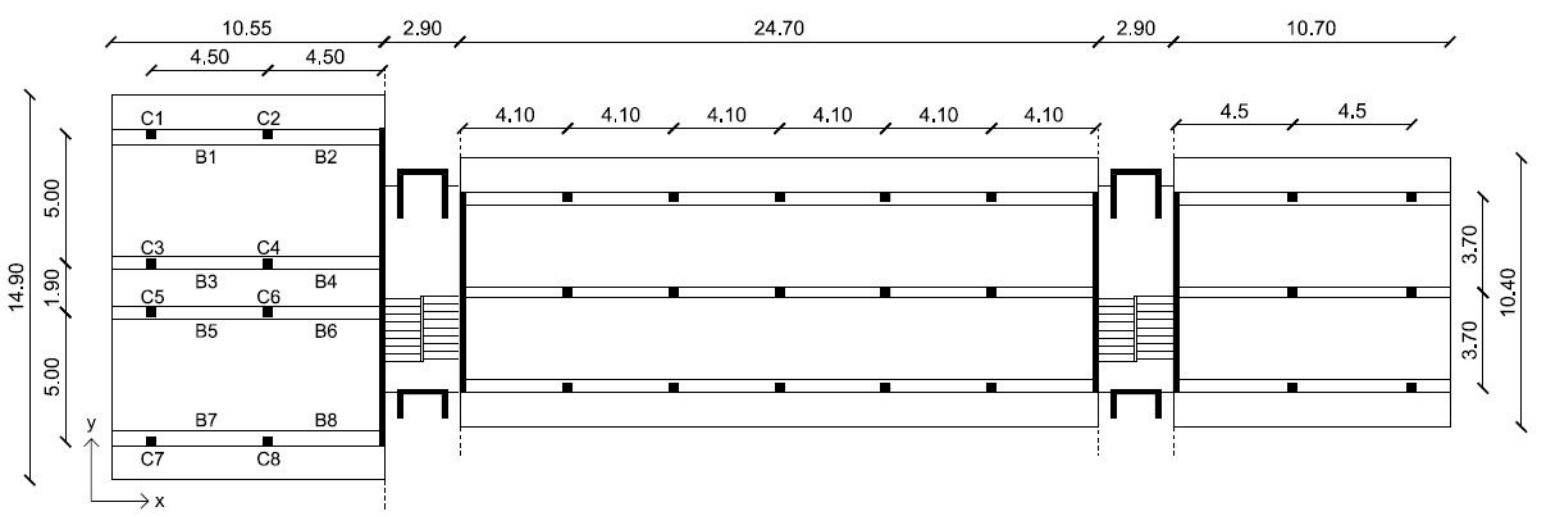

Figure 13. Plan of the first floor of building B. 
It is a six-story building having a rectangular plan, with approximate dimensions of $50 \times 10 \mathrm{~m}^{2}$. The building can be divided into three main blocks plus two staircases, separated from each other by the seismic joints that are indicated by dotted lines in Figure 13. The two lateral blocks have no infill walls on the ground floor, while in the central block there are masonry infill walls between the perimeter ground floor columns, with a continuous strip window at the top.

The bearing structure of the central block is made of two RC walls in the y direction, positioned at the ends of the block, and three RC frames in the X direction. Structural walls are 20-cm thick. Columns have a square section of $35 \times 35 \mathrm{~cm}^{2}$ on the ground floor, and $30 \times 30 \mathrm{~cm}^{2}$ on the upper floors. The longitudinal reinforcement of the column is made by $4 \Phi 16$, one for each corner, for all the levels. In the two lateral blocks, the bearing structure is characterized by a single RC wall in the $\mathrm{Y}$ direction and, in the $\mathrm{X}$ direction, by three $\mathrm{RC}$ frames in the right-side block, and four RC frames in the left side one. As for the central block, columns have a square section of $35 \times 35 \mathrm{~cm}^{2}$ on the ground floor, and $30 \times 30 \mathrm{~cm}^{2}$ on the upper floors. The longitudinal reinforcement of columns C1, C3, C5 and C7 in Figure 13 on the ground and first floor consists of two layers, each made by $3 \Phi 20$ parallel to y direction. On the second floor, the longitudinal reinforcement of the same columns consists of $6 \Phi 16$, distributed in two layers, each layer made of three bars, parallel to y directions; on the other floors, the longitudinal bars are reduced to $4 \Phi 16$, one bar for each corner. The reinforcement of $C 2$ and $C 8$ on the ground floor consists of $8 \Phi 20$, three parallel to each side; in the same orientation, there are $8 \Phi 16$ on the first floor. On the second floor, longitudinal reinforcement consists of a total of $6 \Phi 16$, divided into two layers of three bars parallel to the longer side of the section. On the other floors, reinforcement consists of $4 \Phi 16$, one for each corner. The longitudinal reinforcement of columns $C 4$ and $\mathrm{C} 6$ on the ground floor comprises $4 \Phi 20$, one for each corner; this is reduced to $4 \Phi 16$ on the other floors. The transverse reinforcement of the columns consists of $\Phi 6$ every $17.5 \mathrm{~cm}$.

In all the blocks, interior beams have a section of $50 \times 23.5 \mathrm{~cm}^{2}$, while perimeter beams have a section of $60 \times 23.5 \mathrm{~cm}^{2}$. There are no secondary beams in $Y$ directions. On the under-roof floor, which is not practicable, beams have section of $40 \times 15.5 \mathrm{~cm}^{2}$. Frame elements of the central and the right block have the same dimensions as those of the left block. Floors are made of precast RC joists, oriented in the $Y$ direction, having a depth of $20.5 \mathrm{~cm}$ and an interaxle spacing of $25 \mathrm{~cm}$, completed with clay bricks and a cast-in-place concrete slab 3-cm thick.

According to [14], the two lateral blocks of the building are irregular both in plan and along the height. The irregularity in plan is due the fact that the floors cannot be considered infinitely stiff in their plane, because they have an RC slab of only $3 \mathrm{~cm}$, thinner than $4 \mathrm{~cm}$, which is the minimum value required by [14]. The irregularity along the height is due to the stiffness decrease of about $40 \%$ between the first and the second floor in the X direction, due to the reduction in the columns' section. Moreover, the two lateral blocks are not torsionally stiff, according to the definition given in Section 3.4.

Based on the acquired data, the concrete cylindrical characteristic compressive strength is assumed equal to $26.5 \mathrm{MPa}$, hence the average strength is $26.5+8=34.5 \mathrm{MPa}$. The reinforcing bars are of the type Aq50, hence they have a characteristic yield strength equal to $264.9 \mathrm{MPa}$ [24], and their average strength can be calculated as $264.9 \times 1.125=298 \mathrm{MPa}$ [14].

Based on the knowledge of the building, a level of knowledge LC2 is assumed [14] for the analysis and the verifications, with the confidence factor $F C=1.2$. Therefore, the concrete compressive strength to be used for ductile mechanism verifications is equal to $34.5 / 1.2=28.8 \mathrm{MPa}$ and for brittle mechanism verifications $34.5 /(1.2 \times 1.5)=19.2 \mathrm{MPa}$. The design yielding strength of steel to be used for ductile mechanism verifications is equal to 298/1.2 $=248.3 \mathrm{MPa}$ and for brittle mechanism verifications $298 /(1.2 \times 1.15)=215.9 \mathrm{MPa}$.

Gravity loads are represented by a dead load of $4 \mathrm{kN} / \mathrm{m}^{2}$ on the story floors and $2.35 \mathrm{kN} / \mathrm{m}^{2}$ on the under-roof floor. Infill walls are considered assuming a linearly distributed load of $7.15 \mathrm{kN} / \mathrm{m}$ acting on the beams below. Live loads are equal to $2 \mathrm{kN} / \mathrm{m}^{2}$ on all the story floors, $4 \mathrm{kN} / \mathrm{m}^{2}$ on balconies and staircases, $0.5 \mathrm{kN} / \mathrm{m}^{2}$ on the under-roof floor, and $1.2 \mathrm{kN} / \mathrm{m}^{2}$ on the horizontal projection of the roof due to the snow. 


\subsection{Results of the Modal and FNA Analyses}

As previously observed, the building can be divided into two lateral blocks and a central one, independent from each other, due to the presence of the seismic joints (Figure 13). Analysis of the two lateral blocks showed that the left one had the more stressed members, especially the columns further away from the concrete wall. Hence, only the analysis of the left lateral block is presented in the following. Modal analyses are performed separately for the central block and the left lateral one, and the corresponding results are shown in Tables 3 and 4, respectively, where the properties of the main modes are reported.

Table 3. Modal parameters of the central block of building B.

\begin{tabular}{ccccc}
\hline \multirow{2}{*}{ Vibration Mode } & Period & \multicolumn{3}{c}{ Modal Participating Mass Ratios } \\
\cline { 2 - 5 } & $\mathbf{( s )}$ & $\mathbf{U x}$ & $\mathbf{U y}$ & $\mathbf{R z}$ \\
\hline 1 & 1.13 & 0.79 & 0.0 & 0.0001 \\
2 & 0.39 & 0.0 & 0.79 & 0.0 \\
4 & 0.27 & 0.0 & 0.0 & 0.74 \\
\hline
\end{tabular}

Table 4. Modal parameters of the left lateral block of building B.

\begin{tabular}{ccccc}
\hline \multirow{2}{*}{ Vibration Mode } & Period & \multicolumn{3}{c}{ Modal Participating Mass Ratios } \\
\cline { 2 - 5 } & $\mathbf{( s )}$ & $\mathbf{U x}$ & $\mathbf{U y}$ & $\mathbf{R z}$ \\
\hline 1 & 1.82 & 0.0 & 0.32 & 0.50 \\
2 & 0.84 & 0.02 & 0.0 & 0.0 \\
7 & 0.28 & 0.0 & 0.41 & 0.28 \\
\hline
\end{tabular}

For the central block, Table 3 shows that the vibration modes 1 and 2 are purely translational along the $X$ and $Y$ directions, respectively. Mode 4 is purely rotational around the vertical axis $Z$. Hence, thanks to its symmetry in plan and along the height, the central block is not affected by irregular torsional behavior.

For the left lateral block, Table 4 shows that mode 1 is rotational around the vertical axis $\mathrm{Z}$ and mixed translational along $Y$; mode 2 is translational along $X$, and mode 7 is translational along $Y$ and mixed rotational around $\mathrm{Z}$. These results highlight that the lateral block is affected by torsional components of response, which are due to the asymmetric distribution of the vertical structural elements in plan.

Since this research investigates the improvement of buildings' irregular behavior obtained by the introduction of dissipative devices, only the left lateral block of the building is considered in the following. This is due to the fact that most of the checks for the central block are verified, and only local improvements are needed.

As for building A, an FNA is carried out to analyze the lateral block of building B. A preliminary hypothesis of mechanisms that could occur in the existing structure subjected to earthquake has been developed from the analysis of the drawings of the building, technical reports and a site visit. The large spacing of transverse reinforcement $(17.5 \mathrm{~cm})$ at the ends of the columns could lead to shear brittle collapse. Moreover, at the base of the lateral blocks there are no infill walls, and this suggests the possibility of developing a soft story mechanism.

All the results of the verifications for beams and columns are shown in Figures 14-17, where the ratio between demand and capacity is reported in the vertical axis, and the names of the members shown in Figure 13 are reported in the horizontal axis. 


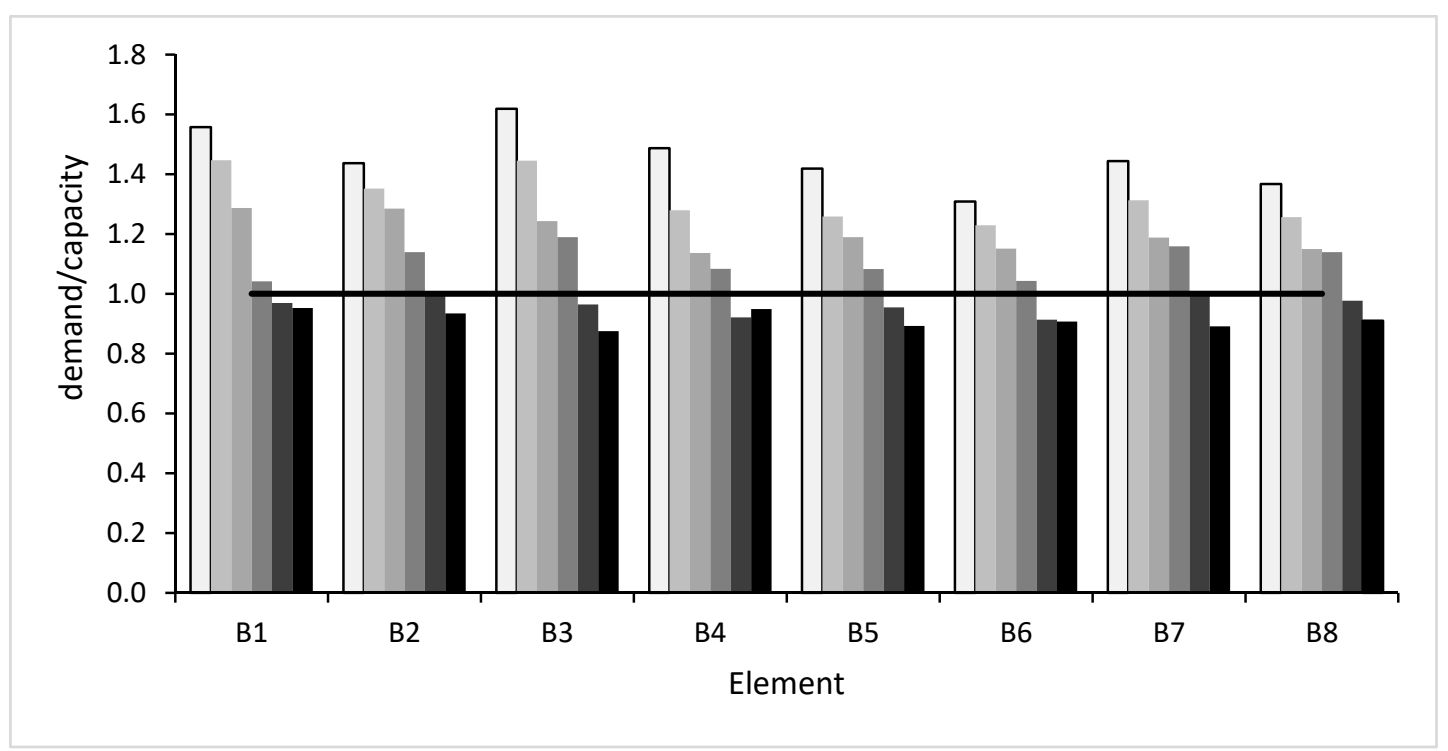

Figure 14. Bending verifications of beams in as-built conditions.

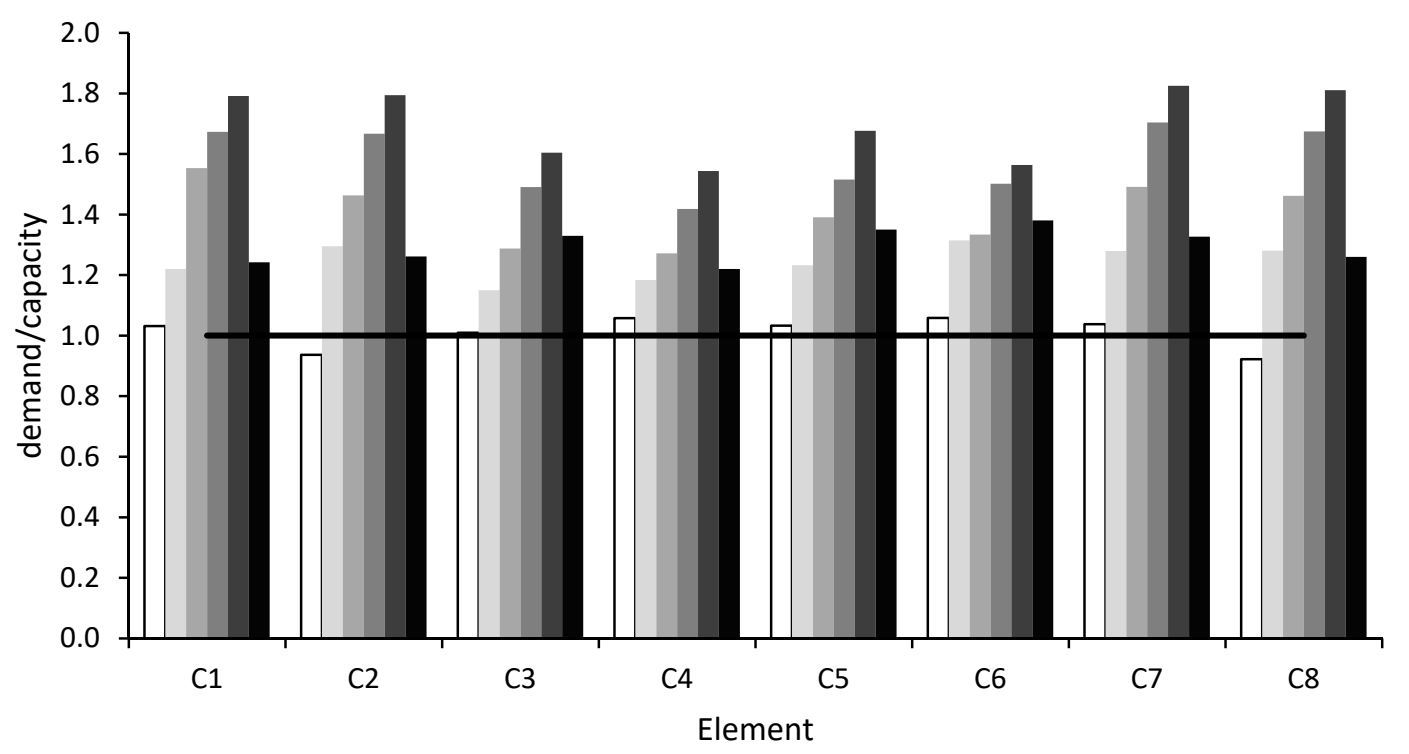

Figure 15. Combined bending and compression verifications of columns in as-built conditions.

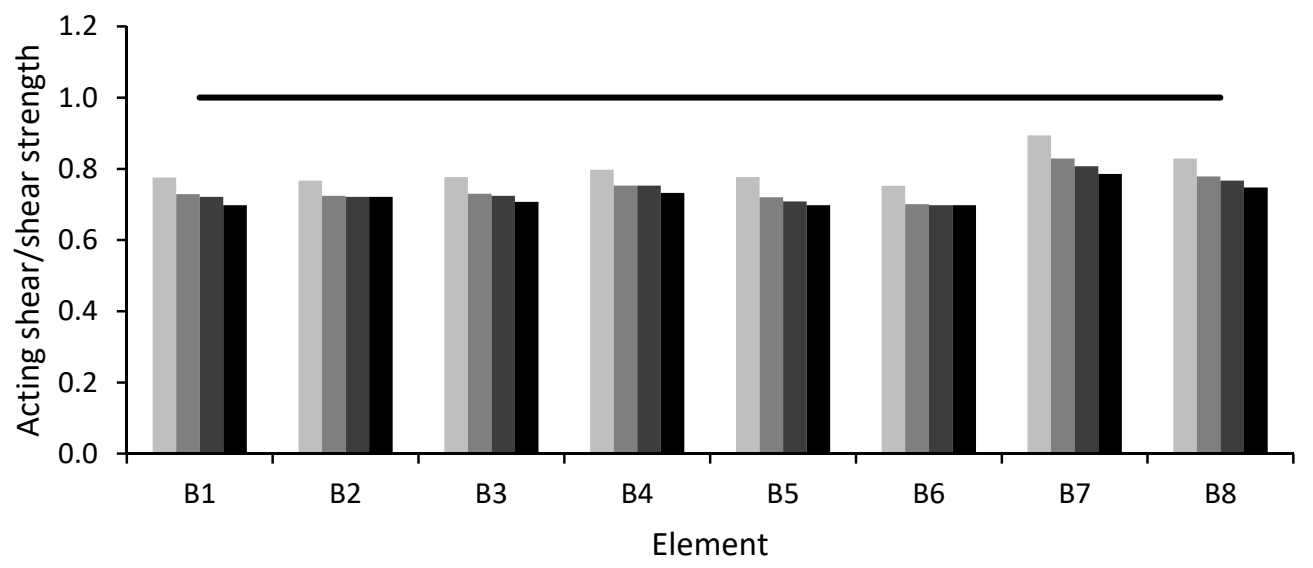

Figure 16. Shear verifications of beams in as-built conditions. 


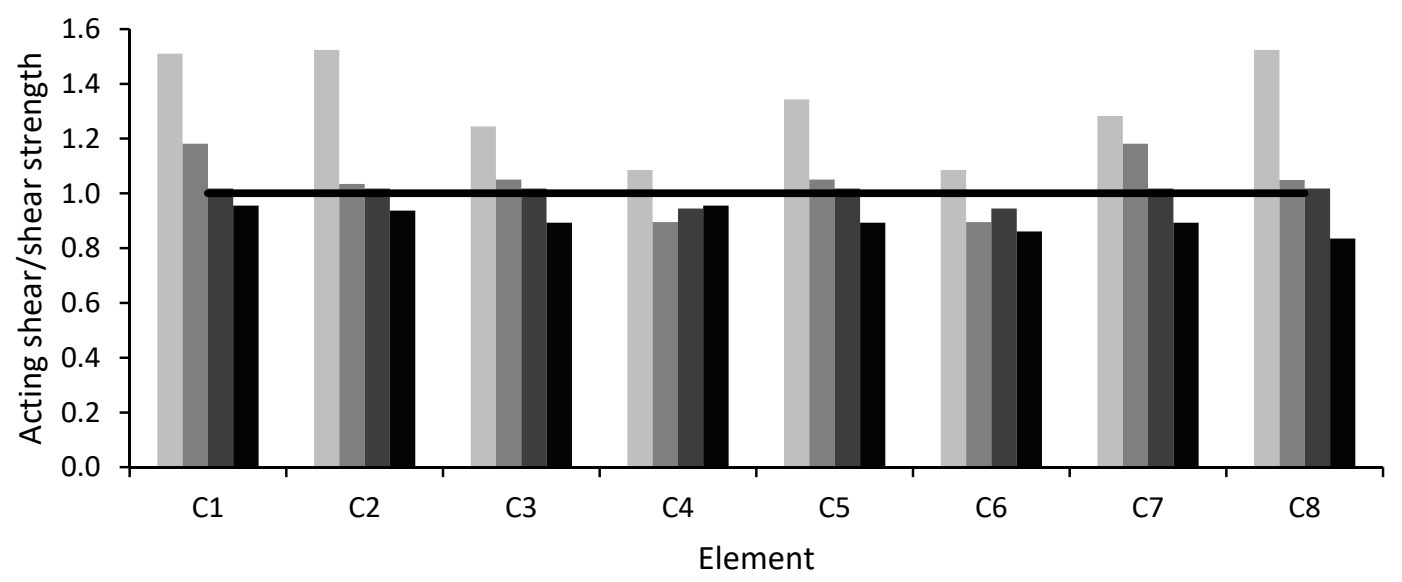

Figure 17. Shear verifications of columns in as-built conditions.

From Figure 14 it can be observed that all beams from the first to the fourth story are not verified for ductile mechanism and, in the worst case, the acting bending moment is more than 1.6 times the bending capacity. All beams of the fifth and sixth floors satisfy the ductile mechanism verification.

In Figure 15, ductile verifications for columns of the lateral block are reported. It can be seen that the only elements that satisfy these verifications are columns $\mathrm{C} 2$ and $\mathrm{C} 8$ at the base, which have the sections with the greatest amount of reinforcing bars. For each column it is possible to observe that the ratio between demand and capacity increases with the height, because the resisting moment of the columns decreases. From Figure 16, it is possible to observe that all beams of the lateral block satisfy shear verifications.

From Figure 17 it can be observed that none of the first-level columns satisfy the shear verification and, in the worst case, the acting shear is 1.52 times greater than the shear strength. This is due to the presence of a small amount of transverse reinforcement in the columns and a great shear force at the building base. On the second level only two columns are verified, and the more eccentric second-level columns, with respect to the center of mass of the plan (C1 and $\mathrm{C} 7)$, exhibit the maximum value of the acting shear/shear strength ratio. At this level most columns do not satisfy the verification, because there is a reduction in the section from the ground floor to the first floor and a consequent strength reduction. On the upper levels, the columns are mostly verified.

In conclusion, the seismic analysis carried out on this case study shows that a lot of bearing elements do not satisfy the verifications required by the Italian Building Code [14] for existing buildings. This is due to the characteristics of structural members and also to the marked torsional behavior of the structure.

\subsection{Retrofit Intervention with Viscous Fluid Dampers and Effects}

Viscous fluid dampers (Jarret type) are viscoelastic fluid passive energy dissipation devices, whose response is dependent upon frequency. They can be used for protection from both wind and earthquake loads, because they develop energy dissipation also for small deformations.

The device consists of a holeless piston that can move inside a cylinder filled with a viscoelastic fluid. The relative movement between the piston and the external cylinder causes the flowing of the fluid through the thin annular space found between the piston head and the internal casing [7]. In this way the fluid is opposed to the motion of the piston, dissipating energy. The damping properties depend strictly on this orifice effect [27].

The fluid used is a silicon-based elastomeric material that provides an additional stiffness in addition to the damping. This characteristic is useful when the intent is not only to dissipate the input energy, but also to stiffen the structure. The viscous forces are out of phase with the forces dependent on the movement. In this way, the force in the device does not add to the others that develop in the elements. 
A finite element model of a Jarret damper is obtained using Maxwell's scheme, i.e., using the parallel combination of a non-linear damper element and an elastic spring one. In SAP2000, these two elements can be implemented with the Nlinks "damper-exponential" and "spring", respectively. The spring takes account of the elastic component of device strains, while the damper-exponential models the non-linear viscous behavior of the fluid, which is described by the following force-velocity relationship, Equation (14):

$$
F=c \cdot \operatorname{sgn}[\dot{x}(t)]|\dot{x}(t)|^{\alpha}
$$

where $F$ is the force component due to the fluid non-linear viscosity, sgn is the signum of the function, $\dot{x}$ is the instantaneous velocity of the piston rod, $c$ is the damping coefficient and $\alpha$ is the damping exponent.

In the current study, $\alpha$ equal to 0.15 and c equal to $85 \mathrm{kN}(\mathrm{s} / \mathrm{m})^{0.15}$ are used. As shown in the previous section, the verifications required by [14] are not satisfied due to both the characteristics of the structural members and the torsional behavior of the building lateral block. To regularize this behavior and reduce the seismic vulnerability, the viscous fluid dampers of Jarret type BC5A-105 are used as a retrofit solution. Pairs of dissipative devices are mounted at the tops of concentric V-shaped steel braces. The braces are connected to the concrete frame by metal anchors. The disposition of Jarret dampers, shown in Figure 18, is the result of a comprehensive design process, whose goal is the best performance behavior of the dissipative system.

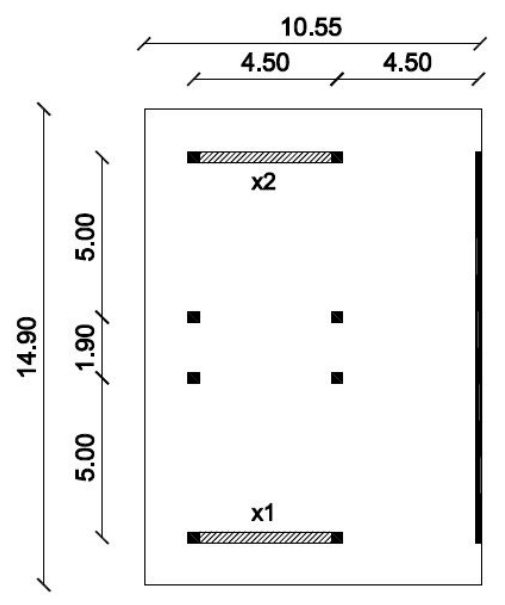

(a)

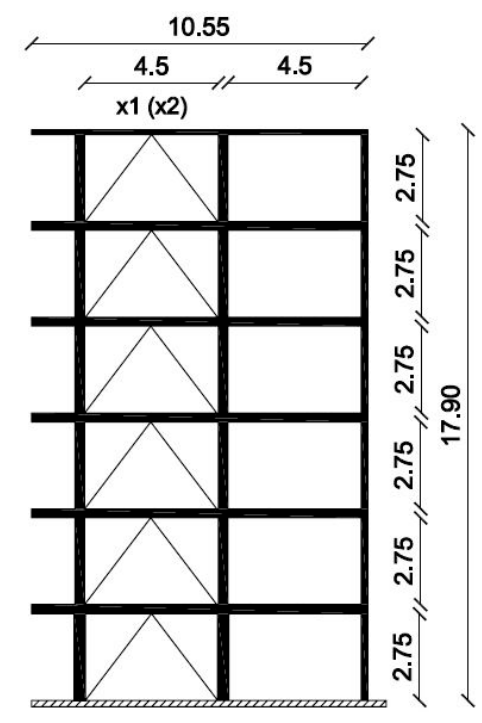

(b)

Figure 18. Distribution of Jarret devices in: (a) plan and (b) elevation.

Thus, the braces are inserted in the direction of least seismic resistance of the structure (x direction). They are positioned in the perimeter frames, to increase the torsional stiffness of the building. It is not possible to introduce a brace in the left external bay in y direction, because this bay is inside the housing unit. Although the building resistance in this direction is already mainly assured by the structural wall, to place a dissipative brace in this position would have served to re-align the center of rigidity with the center of mass.

As expected, the use of the viscous fluid dampers produces a reduction in the energy absorbed by the building (Figure 19). 


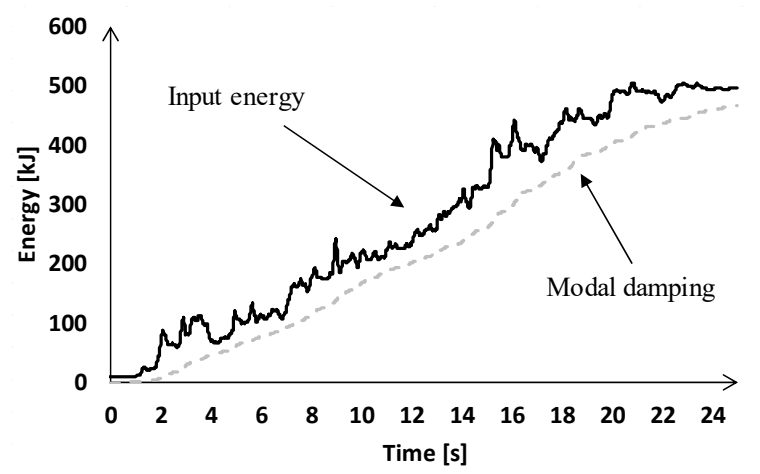

(a)

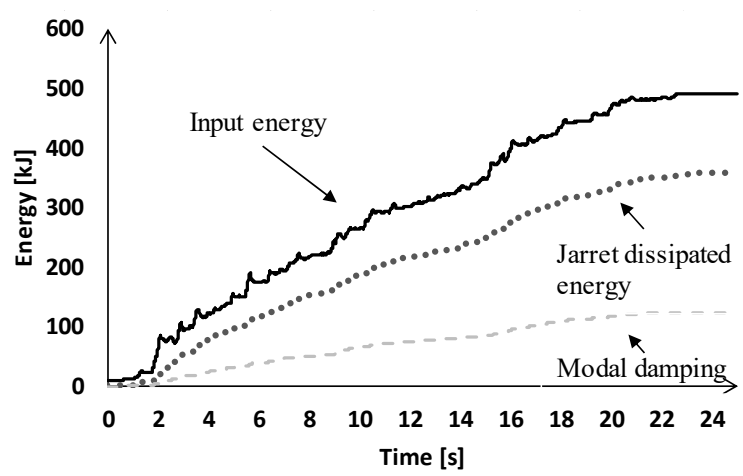

(b)

Figure 19. Energy diagrams for building B in: (a) as-built configuration and (b) after retrofit.

In fact, as shown in Figure 19b, 82\% of the total input energy is absorbed by the 12 pairs of Jarret devices, while the remaining $18 \%$ is dissipated by the building through modal damping. In this way, the forces acting on the structural members result lower than in the as-built configuration.

As regards the devices' verification, the maximum displacement allowed by the dampers is $105 \mathrm{~mm}$. In Figure 20, the cyclic force-displacement responses obtained under the MCE for the most stressed devices are plotted.
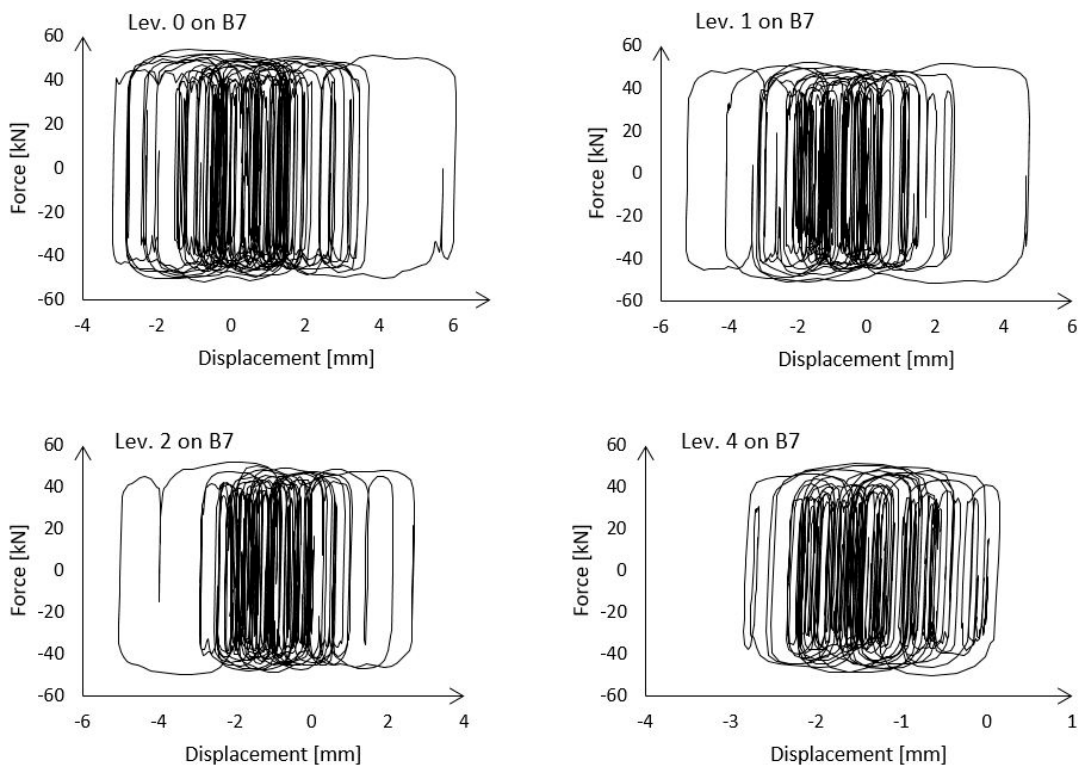

Figure 20. Response cycles of the most stressed dampers under an accelerogram of the MCE.

The device peak displacement is obtained using the same procedure employed for building A. The highest peak displacement is $7.7 \mathrm{~mm}$ lower than the admitted value. Hence, the verification is satisfied. Verifications of the building B structural members are performed similarly to the first case study, for the BDE. Figure 21 shows that, after the introduction of dissipative devices, all the beams satisfy the ductile verifications. 


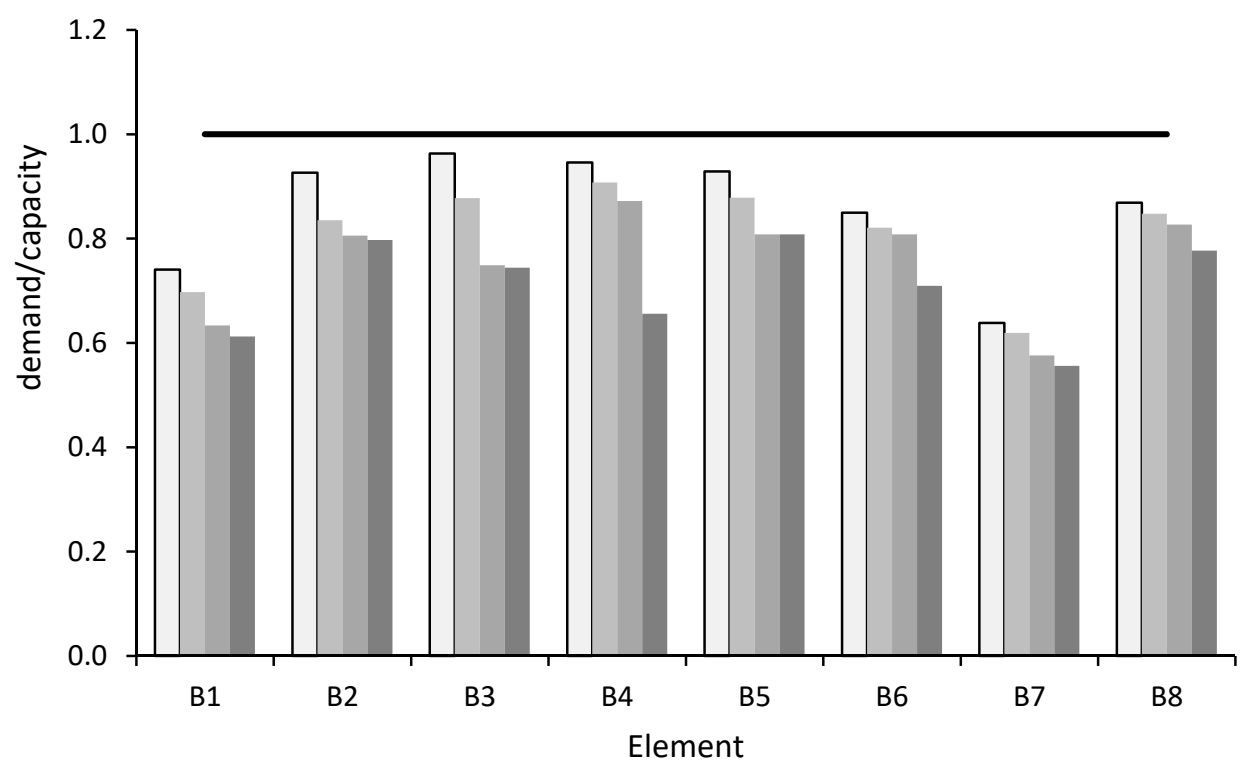

Figure 21. Bending verifications of beams after retrofit.

The bending moment of the most stressed beam, which is B1 on the first floor, passes from a value of $162.8 \mathrm{kN} \cdot \mathrm{m}$ to $77.4 \mathrm{kN} \cdot \mathrm{m}$, with a reduction of $53 \%$. The ratio between demand and capacity, which in the as-built configuration is equal to 1.62 , reduces to a value of 0.74 , after the retrofit. On average, the reduction in the acting bending moment for beams is $43 \%$.

In Figure 22, it is possible to see that after retrofit, the columns also satisfy the ductile verifications.

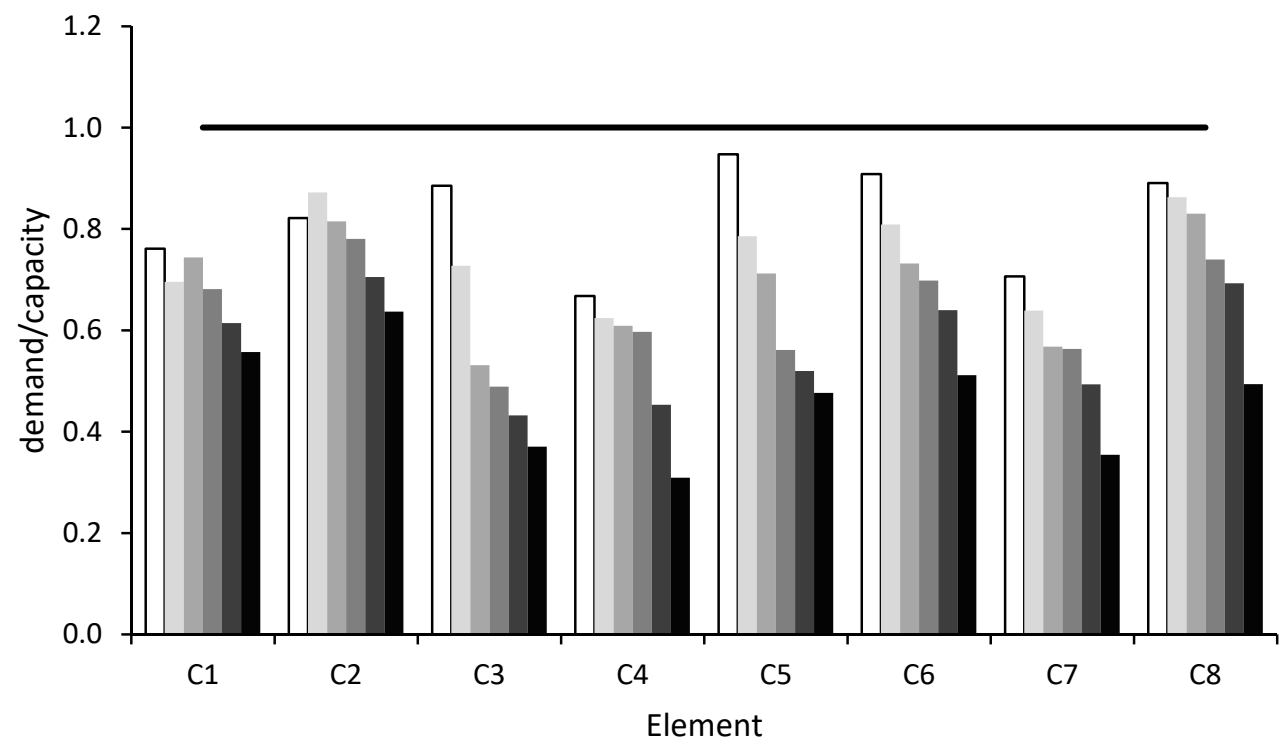

Figure 22. Ductile verifications after retrofit of columns.

In the as-built configuration the most stressed column, $\mathrm{C} 1$, has a bending moment at the base equal to $321.4 \mathrm{kN} \cdot \mathrm{m}$, which reduces to $109.6 \mathrm{kN} \cdot \mathrm{m}$ after retrofit. Shear verifications of beams were all already satisfied in the as-built configuration, as shown in Figure 16.

Figure 23 shows that shear verifications of all columns are satisfied after the introduction of the viscous fluid dampers. On average, the reduction in the acting shear of columns is $58 \%$. 


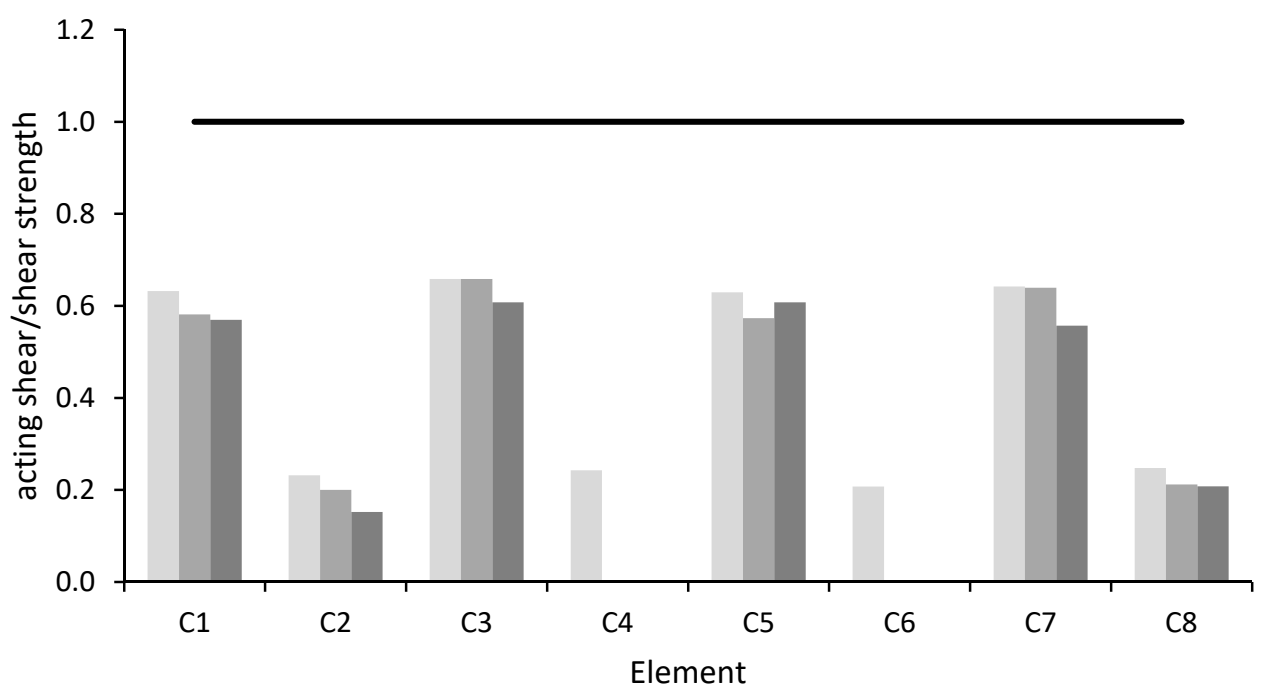

Figure 23. Columns' shear verifications, after retrofit.

\subsection{Building Torsional Stiffness}

For building B, the torsional behavior of the lateral blocks is one of the main issues to be faced in order to improve the building seismic behavior. For this reason, the retrofit intervention by the introduction of steel braces with viscous fluid dampers is aimed not only at reducing the seismic energy dissipated by the building, but also at improving the torsional behavior of the lateral block. To attain this goal, the braces are placed in the structure symmetrically along the perimeter (Figure 18).

As was done for the first case study, the torsional stiffness, $K_{t o r}$, of all floors in the as-built condition and after retrofit is calculated (Table 5).

Table 5. Comparison of torsional stiffness and deformability of building B before and after retrofitting.

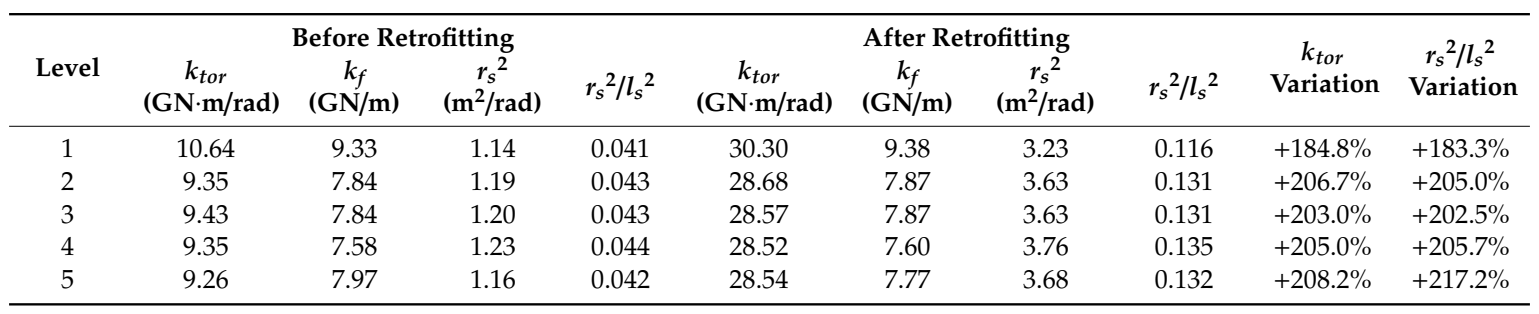

The values of $K_{\text {tor }}$ reported in Table 5 show that, after retrofit, the torsional stiffness of the floors increases to values that range from about $185 \%$ to $208 \%$ of the as-built stiffness. In this way, the torsional behavior of the lateral block exhibits great improvement after the retrofit.

For building $\mathrm{B}, l_{s}{ }^{2}=27.8 \mathrm{~m}^{2}$. The values of the ratio $r_{s}{ }^{2} / l_{s}{ }^{2}$ are calculated as explained in Section 3.4., and the obtained results are shown in Table 5 . In the as-built configuration, the $r_{s}^{2} / l_{s}^{2}$ ratio is about 0.04 for all floors. This is a value lower than 1.0, hence the building is considered torsionally deformable according to [14]. After retrofit, the ratio increases to the value of 0.12 for the first floor and 0.13 for the others, with variations ranging from about $+183 \%$ to about $+217 \%$, respectively. The final values of the ratio are not sufficient to consider the building not torsionally deformable. Nevertheless, the increase is substantial and demonstrates an improvement in the building torsional behavior. Thus, it is possible to say that the use of dissipative devices is beneficial not only to absorb part of the input energy and reduce the force acting on bearing structures, but also to improve the building behavior by reducing negative effects due to its irregularities. 


\section{Conclusions}

Retrofit interventions on two public housing buildings, both irregular in plan and elevation and designed for gravity loads only, have been proposed in this paper. Both interventions have been designed with dissipative devices: BRADs for building A and viscous fluid dampers for building B. In both cases, differences in plan and elevation dispositions of devices have been analyzed. The optimized distribution of the devices, allowing the maximum energy dissipation and the best behavior of the building under seismic action, is presented. Modal and FNA analyses have been performed on the FEM models of the buildings both in the as-built and retrofitted configurations.

On the basis of the performed studies, the following conclusions can be drawn:

1. The verifications performed according to the Italian Building Code prescriptions for existing buildings show that many structural members of irregular buildings designed without anti-seismic criteria are not satisfied. This is mainly due to insufficient transverse reinforcement of the members and column deformations caused by the additional displacements that arise from the building torsional behavior.

2. To increase the torsional stiffness of the building, the steel braces where the dissipative devices are mounted should be placed, if at all possible, in the perimeter frames.

3. Since the shear acting on the building due to seismic action decreases along the height, the use of devices that become progressively smaller and less stiff along the height optimizes the performance of the dissipative system.

4. The dissipative systems designed for the two case studies adhere as much as possible to the previous principles and:

- Are able to absorb more than $50 \%$ of the seismic input energy for building $\mathrm{A}$, and more than $80 \%$ of that for building B, thus reducing the forces acting on the existing building structural members;

- Increase the building torsional stiffness by about $7 \%$ for building $\mathrm{A}$, which already had a good initial value of this parameter, and by more than $200 \%$ for building $B$, thus reducing the columns displacements, and consequently, their stresses;

- Increase the ratio $r_{s}^{2} / l_{s}^{2}$, which is a measure of the building torsional deformability, by about $7 \%$ for building $\mathrm{A}$ and about $200 \%$ for building B, which was initially very torsionally deformable.

5. Thanks to the introduction of the dissipative systems, the reduction in the acting shear is $64 \%$ for the columns of building $\mathrm{A}$, and $65 \%$ for the columns of building $\mathrm{B}$.

Author Contributions: Conceptualization, M.P.; methodology, M.P.; software, M.M., C.D.M. and G.F.; validation, M.M.; formal analysis, M.P. and M.M.; investigation, M.M., C.D.M. and G.F.; data curation, M.M., C.D.M. and G.F.; writing — original draft preparation, M.M.; writing — review and editing, M.P.; visualization, M.M.; supervision, M.P. All authors have read and agreed to the published version of the manuscript.

Funding: This research was funded by Dipartimento della Protezione Civile, Presidenza del Consiglio dei Ministri (DPC-RELUIS 2019-2021), Italy, grant number "prot. n 60 del 05/02/2019".

Acknowledgments: This research has been funded by Italian Department of Civil Protection (within the framework of Executive Project DPCReLUIS 2019-2021), whose support is greatly appreciated.

Conflicts of Interest: The authors declare no conflict of interest. The funders had no role in the design of the study; in the collection, analyses, or interpretation of data; in the writing of the manuscript, or in the decision to publish the results. 


\section{References}

1. Barbieri, G.; Biolzi, L.; Bocciarelli, M.; Fregonese, L.; Frigeri, A. Assessing the vulnerability of historical building. Eng. Struct. 2013, 57, 523-535. [CrossRef]

2. O'Reilly, G.; Sullivan, T.J. Modeling techniques for the seismic Assessment of the existing Italian RC frame structures. J. Earthq. Eng. 2017, 23, 1262-1296. [CrossRef]

3. Ricci, P.; De Luca, F.; Verderame, G.M. 6th April 2009 l'Aquila earthquake, Italy: Reinforced concrete building performance. Bull. Earthq. Eng. 2011, 9, 285-305. [CrossRef]

4. Verderame, G.M.; Iervolino, I.; Ricci, P. Report on the Damages on Buildings Following the Seismic Event of 6th of April 2009, V1.20. Available online: http://www.6aprile.it/docs/Articoli/TerremotoAQ/Reluis/ Rapporto_fotografico_V1.2.pdf (accessed on 29 January 2020).

5. Celano, F.; Cimmino, M.; Coppola, O.; Magliulo, G.; Salzano, P. Report Dei Danni Registrati a Seguito Del Terremoto Del Centro Italia Del 24 Agosto 2016 (Release 1). Available online: http://www.reluis.it/images/ stories/Centre\%20Italy\%20earthquake\%20damage\%20report\%20-\%20R1.pdf (accessed on 30 January 2020). (In Italian).

6. Menna, C.; Frascadone, R.; Moroni, C.; Lignola, G.P.; De Martino, G.; Salzano, A.; Di Ludovico, M.; Prota, A.; Manfredi, G.; Cosenza, E. Rapporto Fotografico Relativo ai Danni Subiti da Alcuni Edifici a Seguito Del Sisma Del Centro Italia Del 2016. Available online: http://www.reluis.it/images/stories/report\%20fotografico\% 20sisma\%20agosto\%202016_31_08_Finale.pdf (accessed on 30 January 2020). (In Italian).

7. Sorace, S.; Terenzi, G. Dissipative bracing-based seismic retrofit of R/C school buildings. Open Constr. Build. Technol. J. 2012, 6, 334-345. [CrossRef]

8. Almeida, A.; Ferreira, R.; Proença, J.M.; Gago, A.S. Seismic retrofit of RC building structures with Buckling Restrained Braces. Eng. Struct. 2016, 130, 14-22. [CrossRef]

9. Mazza, F. Nonlinear seismic analysis of r.c. framed buildings with setbacks retrofitted by damper braces. Eng. Struct. 2016, 126, 559-570. [CrossRef]

10. Sabelli, R.; Mahin, S.; Chang, C. Seismic demands on steel braced frame buildings with buckling-restrained braces. Eng. Struct. 2003, 25, 655-666. [CrossRef]

11. Di Sarno, L.; Manfredi, G. Seismic retrofitting with buckling restrained braces: Application to an existing non-ductile RC frame building. Soil Dyn. Earthq. Eng. 2010, 30, 1279-1297. [CrossRef]

12. Sutcu, F.; Takeuchi, T.; Matsui, R. Seismic retrofit design method for RC buildings using buckling-restrained braces and steel frames. J. Constr. Steel Res. 2014, 101, 304-313. [CrossRef]

13. Bai, J.; Ou, J. Earthquake-resistant design of buckling-restrained braced RC moment frames using performance-based plastic design method. Eng. Struct. 2015, 107, 66-79. [CrossRef]

14. Ministero delle Infrastrutture e dei Trasporti. DM 17 gennaio 2018. Aggiornamento delle “Norme tecniche per le costruzioni". Gazzetta Ufficiale, 20 February 2018. n. 42. (In Italian)

15. Ministero delle Infrastrutture e dei Trasporti. 21 gennaio 2019, n. 7 C.S.LL.PP.-Istruzioni per l'applicazione dell' «Aggiornamento delle "Norme tecniche per le costruzioni"» di cui al decreto ministeriale 17 gennaio 2018. Gazzetta Ufficiale, 11 February 2019. n. 35. (In Italian)

16. Samoilă, D.M. Analytical Modelling of Masonry Infills. Acta Tech. Napoc. Civ. Eng. Arch. 2012, 55, 127-136.

17. Moretti, M.L. Seismic design of masonry and reinforced concrete infilled frames: A comprehensive overview. Am. J. Eng. Appl. Sci. 2015, 8, 748-766. [CrossRef]

18. Syrmakesis, C.; Vratsanou, V. Influence of infill walls to RC frames response. In Proceedings of the 8th European Conference on Earthquake Engineering, Istanbul, Turkey, 19-12 September 1986; pp. 475-483.

19. Schmidt, T. An approach of modeling masonry infilled frames by the f.e. method and a modified equivalent strut method. Darmst. Concr. Annu. J. Concr. Concr. Struct. 1989, 4, 171-180.

20. Albayrak, U.; Ünlüoğl, E.; Doğab, M. An overview of the modelling of infill walls in framed structures. Int. J. Struct. Civ. Eng. Res. 2017, 6, 24-29. [CrossRef]

21. Tarque, N.; Candido, L.; Camata, G.; Spaccone, E. Masonry infilled frame structures: State-of-art review of numerical modelling. Earthq. Struct. 2015, 8, 225-251.

22. Mainstone, R.J. On the stiffness and strengths of infilled frames. Proc. Inst. Civ. Eng. 1971, 49, 57-90.

23. Regio Decreto-Legge 16 novembre 1939-XVIII n. 2229. Gazzetta Ufficiale, 18 April 1940. n. 92. (In Italian) 
24. Verderame, G.M.; Ricci, P.; Esposito, M.; Sansiviero, F.C. Le caratteristiche meccaniche degli acciai impiegati nelle strutture in c.a. realizzate dal 1950 al 1980. In Proceedings of the XXVI Convegno Nazionale AICAP, Padua, Italy, 19-21 May 2011. (In Italian).

25. Song, T.T.; Spender, B.F., Jr. Supplemental energy dissipation: State-of-the-art and state-of-the-practice. Eng. Struct. 2002, 24, 243-259. [CrossRef]

26. Steel Hysteretic Dampers. Available online: https://www.fipindustriale.it/index.php?area=106\&menu=74\& lingua $=1$ (accessed on 27 October 2020).

27. Terenzi, G. Dynamics of SDOF systems with nonlinear viscous damping. J. Eng. Mech. 1999, 125, 956-963. [CrossRef]

Publisher's Note: MDPI stays neutral with regard to jurisdictional claims in published maps and institutional affiliations.

(C) 2020 by the authors. Licensee MDPI, Basel, Switzerland. This article is an open access article distributed under the terms and conditions of the Creative Commons Attribution (CC BY) license (http://creativecommons.org/licenses/by/4.0/). 